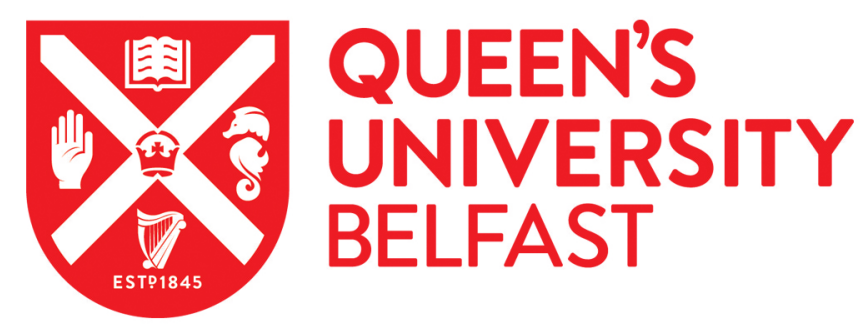

\title{
Comparative biosorption of chromium (VI) using chemically modified date pits (CM-DP) and olive stone (CM-OS): Kinetics, isotherms and influence of co-existing ions
}

Mangwandi, C., Kurniawan, T. A., \& Albadarin, A. B. (2020). Comparative biosorption of chromium (VI) using chemically modified date pits (CM-DP) and olive stone (CM-OS): Kinetics, isotherms and influence of co-existing ions. Chemical Engineering Research and Design. https://doi.org/10.1016/j.cherd.2020.01.034

Published in:

Chemical Engineering Research and Design

Document Version:

Peer reviewed version

Queen's University Belfast - Research Portal:

Link to publication record in Queen's University Belfast Research Portal

\section{Publisher rights}

Copyright 2020 Elsevier.

This manuscript is distributed under a Creative Commons Attribution-NonCommercial-NoDerivs License

(https://creativecommons.org/licenses/by-nc-nd/4.0/), which permits distribution and reproduction for non-commercial purposes, provided the author and source are cited.

\section{General rights}

Copyright for the publications made accessible via the Queen's University Belfast Research Portal is retained by the author(s) and / or other copyright owners and it is a condition of accessing these publications that users recognise and abide by the legal requirements associated with these rights.

\section{Take down policy}

The Research Portal is Queen's institutional repository that provides access to Queen's research output. Every effort has been made to ensure that content in the Research Portal does not infringe any person's rights, or applicable UK laws. If you discover content in the Research Portal that you believe breaches copyright or violates any law, please contact openaccess@qub.ac.uk. 


\title{
Comparative biosorption of chromium (VI) using chemically modified date pits (CM-DP) and olive stone (CM-OS): Kinetics, isotherms and influence of co-existing ions
}

\author{
Chirangano Mangwandi ${ }^{1 *}$, Tonni Agustiono Kurniawan ${ }^{2,}$ Ahmad B. Albadarin ${ }^{3,4}$ \\ ${ }^{1}$ School of Chemistry and Chemical Engineering, Queen's University Belfast, Belfast BT9 5AG, \\ Northern Ireland UK. \\ ${ }^{2}$ Key Laboratory of the Coastal and Wetland Ecosystems (Xiamen University), Ministry of \\ Education, College of the Environment and Ecology, Xiamen University, Fujian 361102, China \\ ${ }^{3}$ Department for Management of Science and Technology Development, Ton Duc Thang \\ University, Ho Chi Minh City, Vietnam \\ ${ }^{4}$ Faculty of Applied Sciences, Ton Duc Thang University, Ho Chi Minh City, Vietnam \\ Email: c.mangwandi@qub.ac.uk
}

\begin{abstract}
Chemically modified date pit (CM-DP) and olive stone (CM-OS) were studied for their biosorption capacity for hexavalent chromium $(\mathrm{Cr}(\mathrm{VI}))$ removal in the aqueous phase. The effect of changing the process conditions, such as the initial $\mathrm{Cr}$ (VI) concentration, $\mathrm{pH}$, biosorbent dosage, ionic strength, presence of other ions and temperature were investigated. It showed that at $\mathrm{pH}=2$, biosorbent dosage $>4 \mathrm{~g} / \mathrm{L}$ and a low ionic strength, both biosorbents showed best biosorption capacity of the Cr(VI) removal. Various isotherm models were applied to fit the experimental data and the Freundlich isotherm model was the best fitting isotherm model for the biosorption experimental data of both biosorbents. The maximum biosorption capacities of CM-DP and CM-OS were found to be 82.63 and $53.31 \mathrm{mg} / \mathrm{g}$ respectively, which is comparable to other materials. In the kinetic study, the pseudo second order model can best describe the biosorption process of both biosorbents and the intraparticle diffusion was not the rate-limiting step indicating the contribution of film diffusion in the $\mathrm{Cr}(\mathrm{VI})$ removal processes.
\end{abstract}

Keywords: Adsorption and Biosorption; Agricultural waste; Heavy metals; Low-cost biosorbents; Water purification.

\section{Introduction}

A huge amount of fresh water is used as a raw material in many industries for cooling purposes and as a mean of production e.g. the world uses 5 trillion litres (1.3 trillion gallons) 
of water each year for fabric dyeing alone. Different kinds of intermediate products and wastes are introduced into the water as it passes through industrial processes thereby producing wastewater. Some of the contaminants in this wastewater are heavy metals which can be easily concentrated in food chains and are harmful to human health and environment $[1,2]$.

Among these heavy metals, chromium is one of the most poisonous and detrimental to human health [3]. Chromium can be released from natural processes such as volcanic activity or rock weathering, and anthropogenic activities such as metallurgical, chemical industries, etc. $[2,4]$. The common oxidation states of chromium in the environment are hexavalent $(\mathrm{Cr}(\mathrm{VI})$, and trivalent $(\mathrm{Cr}(\mathrm{III})$, oxidation states and both of them are environmentally significant. $\mathrm{Cr}(\mathrm{VI})$ is more than 100 times more toxic and 1000 times more mutagenic compared with $\mathrm{Cr}$ (III) [4, 5]. Because of repulsive electrostatic interactions, $\mathrm{Cr}(\mathrm{VI})$ is difficult to be absorbed by negatively charged soil particles, which means that it is very mobile at nearly all $\mathrm{pH}$ range [1, 3]. In the $\mathrm{pH}$ range of natural water, $\mathrm{Cr}(\mathrm{VI})$ exists as the dichromate $\left(\mathrm{Cr}_{2} \mathrm{O}_{7}{ }^{2-}\right)$, hydrogen chromate $\left(\mathrm{HCrO}_{4}{ }^{-}\right)$, or chromate $\left(\mathrm{CrO}_{4}{ }^{2-}\right)$ ions, which are soluble, easy to transfer in water, strongly toxic and even carcinogenic, presumably owing to cell membrane transfer and the formation of harmful intermediate products through direct reduction reaction $[1,4]$. Thus, excessive discharge of $\mathrm{Cr}(\mathrm{VI})$ can cause harm to creatures and the ecosystem [2].

In most of the industrial countries, limits of emission of $\mathrm{Cr}(\mathrm{VI})$ to natural water bodies have been put in place in order to protect the environment. For example in the United States Environmental Protection Agency in 1990 regulated that the maximum discharge value of total chromium is $0.1 \mathrm{mg} / \mathrm{L}$ to water on the surface of the planet and $0.05 \mathrm{mg} / \mathrm{L}$ to water suitable for drinking, and total discharge value is not more than $2 \mathrm{mg} / \mathrm{L} \mathrm{[6]}$. The maximum value in water used for irrigation is recommended to be $100 \mu \mathrm{g} / \mathrm{L}$ by the United Nations Food and Agriculture Organization [7]. Therefore, it is crucial to ensure that $\mathrm{Cr}(\mathrm{VI})$ is removed from the effluents or at least the concentration is reduced to acceptable levels before releasing to the environment. The most widely used method is the reduction of $\mathrm{Cr}(\mathrm{VI})$ to its trivalent state which can be absorbed or deposited as amorphous hydroxide. This method, however, can only be used for disposal of concentrated industrial wastewater and produces a large of an amount of chemical sludge [2].

Among other methods, adsorption and biosorption are widely used in the environmental science field for their comparatively low cost, feasible removal capacity of pollutant and simplicity of design and operation. The application of commercial absorbent, mainly activated carbon and zeolite, which have been proved as the most effective adsorbents for treatment of heavy metal in effluent due to their high surface area, reactive property and microcrystal 
structure $[4,8]$, has one limitation of cost. The global market for adsorbent materials has been valued to be approximately $\$ 11.1$ billion in $2019,38 \%$ and $32 \%$ higher than that in 2013 (\$8.0 billion) and 2014 ( $\$ 8.4$ billion), respectively [9]. The accelerating global demand for clean energy and environmental sustainability urges scientists and engineers to develop innovative materials with superior performance over traditional bench-mark materials.

The use of biosorption as a treatment method for the removal of heavy metal in the aqueous solutions has become popular $[3,4,10-20]$. The metal removal is based on metal ion interaction with the functional groups present in the biomaterial $[1,2,21]$. These biomaterials are available from nature and can effectively remove chromium due to their reductive and adsorptive functional groups. The other option would be to produce low cost activated materials from cheap materials such as rice straw, pectin-rich fruit, peat, sesame stalk, lignin, sawdust, olive oil industry waste, seaweed and other industrial bio-wastes for use as biosorbent material $[1,16,20,22]$. Chemical activation can be used to enhance the biosorption properties of the biosorbent material [23-25].

Date pits (DP) are low-cost and can be obtained in large quantities from numerous countries especially some Mediterranean countries. Date pits have become the largest byproduct in palm growing countries because it accounts for ten percent of total weight [2]. Olive stone (OS) is the by-product of olive oil and table olive production. It is inexpensive with no market value, and abundant in the Mediterranean area, especially in Spain with the annual production of about 800,000 tonnes. Date pits and olive stones are among some of the materials that have been applied as biosorbent material for removal of chromium by our research group and other researchers $[2,16,22,26,27]$.

The objective of this study was to further explore the capacity of chemically modified date pits (CM-DP) and chemically modified olive stones (CM-OS) for $\mathrm{Cr}(\mathrm{VI})$ biosorption. The effect of the process conditions will be investigated and the biosorption mechanism examined by exploring the kinetic and equilibrium studies. The effect of the presence of other ions on the biosorption process is also investigated. This is an extension to our earlier work on application of the materials as alternative materials for the removal of toxic hexavalent chromium $[2,26]$.

\section{Experimental and theoretical section}

\subsection{Chemicals and materials}

Potassium dichromate $\left(\mathrm{K}_{2} \mathrm{Cr}_{2} \mathrm{O}_{7}\right)$ was used to prepare $\mathrm{Cr}(\mathrm{VI})$ stock solution. Hydrochloric acid $(\mathrm{HCl})$ and sodium hydroxide $(\mathrm{NaOH})$ were prepared for the $\mathrm{pH}$ adjustment. Sodium chloride $(\mathrm{NaCl})$ was used in the ionic strength experiment. Sodium chloride $(\mathrm{NaCl})$, 
ammonium chloride $\left(\mathrm{NH}_{4} \mathrm{Cl}\right)$, potassium sulphate $\left(\mathrm{K}_{2} \mathrm{SO}_{4}\right)$, sodium nitrate $\left(\mathrm{NaNO}_{3}\right)$ and Sodium hydrogen carbonate $\left(\mathrm{NaHCO}_{3}\right)$ salts were used for the coexisting ions experiment. Sodium hydroxide, epichlorohydrin, diethylenetriamine (DETA) were used to activate the date pits and olive stones. 1,5-diphenylcarbohydrazide, methanol (HPLC-grade), sulphuric acid solution (98\%) were used to prepare the reagent for measurement of the concentration of $\mathrm{Cr}(\mathrm{VI})$.

\subsection{Methods}

\subsubsection{Activated biomass preparation}

Epichlorohydrin and diethylenetriamine (DETA) were used to activate the DP and OS. Epichlorohydrin is used to epoxidize the biomass by the combination of the oxygen in the hydroxyls and the nitrogen from the amine groups in the biomass. The binding with oxygen improves the crosslinking of the structure making it more mechanically stable. However, the amount of epichlorohydrin used must be controlled since it is capable of decreasing the availability of the amino groups. The activation process is performed in alkaline conditions $[15,25,28]$. DETA is used to introduce the diethylamino groups; it can aid the aminolysis of the epoxide group. Two different solutions with concentrations of $1.25 \mathrm{M}$ and $0.125 \mathrm{M} \mathrm{NaOH}$ were made by dissolving certain quantities of $\mathrm{NaOH}$ in deionized water. $75 \mathrm{~mL}$ of $\mathrm{NaOH}(1.25$ M) with $50 \mathrm{~mL}$ epichlorohydrin were mixed in hot plate stirrer at room temperature and then $5 \mathrm{~g}$ of the biomass (DP or OS) were mixed in the solution at $40{ }^{\circ} \mathrm{C}$ for $30 \mathrm{~min}$ on a hot plate stirrer. After mixing the solution for $30 \mathrm{~min}$, the materials were filtered out, washed several times with deionized water and then dried at $65^{\circ} \mathrm{C}$ for 3 hours. After drying the biomass, 75 $\mathrm{mL}$ of $\mathrm{NaOH}(0.125 \mathrm{M}), 12.5 \mathrm{~mL}$ of DETA and the dried biosorbents were mixed on a hot plate stirrer at $65^{\circ} \mathrm{C}$ for 60 minutes. The activated biosorbents were then washed with deionized water until the $\mathrm{pH}$ of eluent reaching almost neutral, dried for 12 hours at $65{ }^{\circ} \mathrm{C}$ and stored in glass jars labelled as chemically modified olive stone (CM-OS) and date pits (CM-DP).

\subsubsection{Characterisation procedure}

The functional groups of CM-DP and CM-OS were determined by Fourier Transform Infrared (FTIR) Spectroscopy using a Perkin Spectrum 100 within the range $4000-400 / \mathrm{cm}$. The textural properties of the materials were determined using Scanning Electron Microscope (SEM) analysis; samples were coated with gold and vacuumed for electron reflection before the analysis on a JEOL-JSM 6400 scanning microscope. The zeta potential measurements were carried out using a Malvern Zetasizer (3000HS) to determine the point of zero charge (PZC). The Kratos ULTRA spectrometer was used for XPS measurements with the following 
parameters: sample temperature $=20-30{ }^{\circ} \mathrm{C}, \mathrm{X}$-Ray Gun mono $\mathrm{Al} \mathrm{K} \alpha 1482.58 \mathrm{eV}$; $150 \mathrm{~W}(10$ $\mathrm{mA}, 15 \mathrm{kV}$ ) and pass energy $=160 \mathrm{eV}$ for survey spectra and $20 \mathrm{eV}$ for narrow regions.

\subsection{Biosorption experiments}

A number of the factors affecting the biosorption have been studied including initial concentration of $\mathrm{Cr}(\mathrm{VI}), \mathrm{pH}$, biosorbent dosage, ionic strength, co-existing ions, and temperature. Their ranges in this study were: initial concentration (10-200 ppm), pH (2-9), biosorbent dosage $(0.02-0.2 \mathrm{~g} / \mathrm{L})$, ionic strength $(0-2 \mathrm{M})$ and temperature $\left(20-50{ }^{\circ} \mathrm{C}\right)$. When studying the effect of one-factor in an experiment, the other factors remained unchanged for comparison. Initial settings for the factors were: initial concentration $100 \mathrm{ppm}, \mathrm{pH} 2$, activated biosorbent dosage $0.05 \mathrm{~g}$ with $20 \mathrm{~mL}$ solution, ionic strength $0 \mathrm{M}$, no other coexisting ions, room temperature and shaking time 3 days.

The adjustment of $\mathrm{pH}$ was achieved by adding $\mathrm{HCl}$ or $\mathrm{NaOH}$ using a $\mathrm{pH}$ meter for measurement. In the experiments, the solutions with DP or OS were placed in glass jars, sealed firmly and put on a mechanical shaker. A certain volume of the supernatant in the jars was taken after the biosorption and analysed for measurement of the $\operatorname{Cr}(\mathrm{VI})$ concentration on a $\mathrm{HACH}$ meter.

The biosorption isotherm studies were established by the following conditions. For the initial $\mathrm{Cr}(\mathrm{VI})$ concentrations: 10, 25, 50, 75, 100 and $200 \mathrm{ppm}$; solution $\mathrm{pH}$ 2; shaking time 3 days at $110 \mathrm{rpm}$; dosage $2.5 \mathrm{~g} / \mathrm{L}$; and room temperature. For the effect of $\mathrm{pH}$ : $\mathrm{pH} 2-9$; initial $\mathrm{Cr}(\mathrm{VI})$ concentrations $100 \mathrm{ppm}$; shaking time 3 days at $110 \mathrm{rpm}$; dosage $2.5 \mathrm{~g} / \mathrm{L}$; and room temperature. The effect of dosage was studied using a range of 1, 1.5, 2, 2.5, 3 and $3.5 \mathrm{~g} / \mathrm{L}$ and solution $\mathrm{pH}$ 2; initial $\mathrm{Cr}(\mathrm{VI})$ concentrations $100 \mathrm{ppm}$; shaking time 3 days at $110 \mathrm{rpm}$ at room temperature. Salt concentrations of $0,0.05,0.1,0.2,0.5,1$ and $2 \mathrm{M} \mathrm{NaCl}$ were used to study the effect of ionic strength at solution $\mathrm{pH} 2$; initial $\mathrm{Cr}(\mathrm{VI})$ concentrations 100 ppm; shaking time 3 days at100 rpm; dosage $2.5 \mathrm{~g} / \mathrm{L}$; room temperature. $0.1 \mathrm{M} \mathrm{NaCl}, \mathrm{NH}_{4} \mathrm{Cl}, \mathrm{K}_{2} \mathrm{SO}_{4}, \mathrm{NaNO}_{3}$, $\mathrm{NaHCO}_{3}$ and blank were used to study the effect of other ions at the same conditions. The kinetic studies were used to determine the rate of biosorption, and the time required to reach equilibrium. The study was undertaken with an initial $\mathrm{Cr}(\mathrm{VI})$ concentration of $100 \mathrm{ppm}$, solution $\mathrm{pH}$ of 2 and dosage of $2.5 \mathrm{~g} / \mathrm{L}$, at four different temperatures: room temperature (20), 30,40 and $50{ }^{\circ} \mathrm{C}$ in 4 beakers on hot plate stirrers. $1 \mathrm{~mL}$ samples were withdrawn from solution at the chosen time intervals $(0,5,10,15,20,25,30,35,40,45,54,60,101,120,180,240,300$, $360 \mathrm{~min}$ ) diluted and were then analysed used for concentration of $\mathrm{Cr}(\mathrm{VI})$. 


\subsection{Chromium analysis}

The method for measurement of the concentration of $\mathrm{Cr}(\mathrm{VI})$ is a colorimetric standard method established by Gilcreas et al. [7]. To prepare the reagent, $250 \mathrm{mg}$ of 1,5diphenylcarbohydrazide was dissolved in $50 \mathrm{~mL}$ of methanol (HPLC-grade), added to $250 \mathrm{~mL}$ of $\mathrm{H}_{2} \mathrm{SO}_{4}$ solution (contains $14 \mathrm{~mL}$ of $98 \% \mathrm{H}_{2} \mathrm{SO}_{4}$ ) which was diluted with deionised water to $500 \mathrm{~mL}$, and stored at low temperature. The fresh reagent is a very clear solution and can be used for several days until any colour appears [7]. To analyse the $\mathrm{Cr}(\mathrm{VI})$ concentration, firstly, $2 \mathrm{~mL}$ of the reagent was added to $6 \mathrm{~mL}$ of hexavalent solution and then, after waiting for 5 min, the solution was analysed by UV-VIS spectrophotometer at a $540 \mathrm{~nm}$ wavelength. The total $\mathrm{Cr}(\mathrm{Cr}(\mathrm{VI})$ and $\mathrm{Cr}(\mathrm{III}))$ concentrations in the solutions were analyzed by a Perkin-Elmer 2100 atomic absorption spectrophotometer (ICP-AES) at a wavelength of 357.9nm.

\subsection{Determination of $\mathrm{Cr}(\mathrm{VI})$ removal efficiency and modelling}

The percentage removal of $\mathrm{Cr}(\mathrm{VI})$ was calculated using Eq.(1):

$$
\operatorname{Removal}(\%)=\frac{C_{0}-C_{e}}{C_{0}} \times 100 \%
$$

where $C_{\mathrm{o}}$ and $C_{\mathrm{e}}$ are the concentration of the remaining $\mathrm{Cr}(\mathrm{VI})$ at the start and equilibrium, respectively in ppm.

The biosorption capacity $q_{\mathrm{e}}$ is the quantity of adsorbed $\mathrm{Cr}(\mathrm{VI})$ in the solution, which was calculated by the Eq.(2):

$$
q \mathrm{e}=\frac{C_{0}-C_{e}}{m} \times V
$$

where $m$ is the mass of activated biosorbent in $\mathrm{g}$ and $V$ is the volume of the solution (L).

\subsubsection{Kinetic modelling}

For the kinetics of the biosorption process, the pseudo first order as well as the pseudo second order reaction models were used in the study. The two kinetic models are described by Eq. (4) and (5) [1]:

$$
\begin{aligned}
& q=q_{e}\left(1-e^{-k_{1} t}\right) \\
& q=\frac{q_{e}^{2} k_{2} t}{1+q_{e} k_{2} t}
\end{aligned}
$$

where $q$ is the biosorption capacity in $\mathrm{mg} / \mathrm{g}$ at any time, $t(\mathrm{~min}) ; k_{1}$ is the pseudo first order reaction rate constant in $\min ^{-1} ; k_{2}$ is the pseudo second order reaction rate constant in $\mathrm{g} / \mathrm{mg} / \mathrm{min}$.

Intraparticle diffusion and Boyd models were employed for the determination of the diffusion mechanism in the biosorption process [1]. Weber's pore diffusion or intraparticle diffusion 
model is described by Eq. (6):

$$
\mathrm{q}=k_{\text {diff }} t^{0.5}
$$

where $k_{\text {diff }}$ is the rate constant of the intraparticle diffusion in $\left(\mathrm{mg} / \mathrm{g}\right.$ sorbent $\left.\mathrm{x} t^{-0.5}\right)$ which was calculated by plotting $q$ versus $t^{0.5}$. If intraparticle diffusion is the step that can determine the rate, the plot of $q$ versus $t^{0.5}$ is linear and the slope is $k_{\text {diff }}$ with the intersection with the origin. If the plot is not linear, it can be assumed that, in addition to intraparticle diffusion, there are some other mechanisms involved within the biosorption system, such as film diffusion [29].

For characterisation of the actual rate-limiting step for the biosorption process, the Boyd model is employed to determine the rate-controlling step, which can be the film diffusion as boundary layer or particle diffusion as the diffusion within the pores [1, 30]. The Boyd model can be described as [31]:

$$
\frac{q_{t}}{q_{e}}=1-\frac{6}{\pi} \times \exp \left(-B_{t}\right)
$$

To obtain the $\underline{B}_{t}$ values, Eq. (7) can be rearranged as shown by Eq.(8):

$$
B_{t}=-0.4977-\ln \left(1-\frac{q_{t}}{q_{e}}\right)
$$

The $\underline{B}_{t}$ values can be calculated using Eq. (8). The coefficient of determination $\left(R^{2}\right)$ can be obtained from a plot of $B_{t}$ values against time, $t$, to measure the degree of fitting of the model.

\subsubsection{Biosorption isotherm studies}

Six equilibrium models: Langmuir [32], Dubinin-Radushkevich [33], Freundlich [34], Redlich-Peterson [35], Toth [36] and Khan [37] isotherm models were used in the study. To find models that have the best fit to the experimental data, the coefficient of determination $\left(R^{2}\right)$, mean relative error (MRE) and standard error of estimate (SEE) were used. MRE and SEE can be calculated by Eq.(9) and Eq.(10).

$$
\begin{aligned}
& \mathrm{MRE}=\frac{100}{n} \sum\left(\frac{q_{e, \text { exp }}-q_{e, c a l}}{q_{e, \exp }}\right) \\
& \mathrm{SEE}=\sqrt{\frac{\sum\left(q_{e, \text { exp }}-q_{e, \text { cal }}\right)^{2}}{d f}}
\end{aligned}
$$

where $q_{\mathrm{e}, \text { exp }}$ and $q_{\mathrm{e}, \mathrm{cal}}$ are the quantities of $\mathrm{Cr}(\mathrm{VI})$ adsorbed obtained from the experiment and calculation from the equation of the model, respectively. $n$ is the number of the observation of the experiment and $d f$ is the degree of freedom.

The Langmuir isotherm model is widely employed in adsorption studies. Its assumption is that the surface of the adsorbent is uniform and the adsorption sites are equivalent, all the molecules do not interact with each other and adsorption occurs through the same mechanism 
$[19,24]$. The Langmuir model can be described as:

$$
q_{e}=\frac{q_{m} K_{L} C_{e}}{1+K_{L} C_{e}}
$$

where $q_{\mathrm{m}}$ and $K_{\mathrm{L}}$ are the Langmuir constants regarding the biosorption in $\mathrm{mg} / \mathrm{g}$ and the adsorption energy in $\mathrm{L} / \mathrm{g}$, respectively.

The Dubinin-Radushkevich isotherm, as an empirical model, is employed to describe the adsorption of subcritical vapours upon micro-porous solids coming with a pore filling mechanism[38]. The Dubinin-Radushkevich isotherm model can be described as:

$q_{e}=q_{\max } \exp \left(-K_{D R} \varepsilon^{2}\right)$

The parameter $\varepsilon$ is calculated as:

$$
\varepsilon=\mathrm{RT} \ln \left[1+\frac{1}{C_{e}}\right]
$$

where $q_{\mathrm{max}}$ is the quantity of $\mathrm{Cr}(\mathrm{VI})$ adsorbed at the maximum in $\mathrm{mg} / \mathrm{g}, K_{\mathrm{DR}}$ is the DubininRadushkevich constant, $R$ is the gas constant. $T$ is the absolute temperature in Kelvin $(K) . K_{\mathrm{DR}}$ has relation to the average free energy of biosorption $\left(E_{\mathrm{DR}}\right)$, which is the free energy variation of 1 mole adsorbate ion for its migration to the biosorbent surface from infinite distance in the solution. The apparent energy $E_{\mathrm{DR}}$ can be calculated as:

$$
E_{D R}=\frac{1}{\sqrt{2 K_{D R}}}
$$

The Freundlich isotherm model can be described as:

$q_{e}=K_{F} C_{e}^{1 / n}$

where $K_{\mathrm{F}}$ is the Freundlich constant in relation to the biosorption capacity in definition as the adsorption or distribution capacity and it presents the quantity of $\mathrm{Cr}(\mathrm{VI})$ biosorption on the biosorbent per unit concentration at the equilibrium. $1 / n$ is the heterogeneity factor in relation to the adsorption intensiveness.

The Redlich-Peterson isotherm model is widely applied as a middle way between two extremes, which are the Langmuir and Freundlich models. The Redlich-Peterson isotherm model can be described as [39]:

$$
q_{e}=\frac{K_{R} C_{e}}{1+a_{R} C_{e}^{\beta}}
$$

where $K_{\mathrm{R}}, a_{\mathrm{R}}$ and $\beta$ are the Redlich-Peterson isotherm model constants.

The Toth model is an empirical and widely used model, is used for the heterogeneous system. It can be used at the limit of the concentration. The Toth isotherm model can be described as [40]:

$$
q_{e}=\frac{K_{T} C_{e}}{\left(a_{T}+C_{e}^{g}\right)^{1 / g}}
$$


where $K_{\mathrm{T}}, a_{\mathrm{T}}$ and $\mathrm{g}$ are the Toth isotherm model constants. When $g$ equals to 1 , the Toth model can be reduced to the Langmuir model equation.

The Khan isotherm model is generalized. The Khan isotherm model can be described as [41]:

$$
q_{e}=\frac{b_{K} q_{S} C_{e}}{\left(1+b_{K} C_{e}\right)^{a}}
$$

where $b_{\mathrm{K}}$ is the Khan isotherm model constant, $a_{\mathrm{K}}$ is the Khan isotherm model exponent and $q_{\mathrm{S}}$ is the quantity of the $\mathrm{Cr}(\mathrm{VI})$ adsorbed at the maximum.

\section{Results and Discussion}

\subsection{Characterization of biosorbents}

The zeta potential profiles of CM-OS and CM-DP demonstrated a strong $\mathrm{pH}$-dependence with both materials exhibiting positive zeta potential values at pHs lower than 3.9 and 3.5 for CM-OS and CM-DP, respectively. SEM micrographs of fresh and $\mathrm{Cr}(\mathrm{VI})$ loaded modified olive stone and date pit are shown in Figure 1. The existence of uneven/ rough surface topographies with a high number of asymmetric pores is clearly observable. These surface structures will advance an increase in $\mathrm{Cr}(\mathrm{VI})$ reduction and biosorption capacities as a result of the trapping of metal ions on their rough surfaces and large internal surface area. Noteworthy differences in surface morphology are identified before and after $\mathrm{Cr}(\mathrm{VI})$ removal. After biosorption, the images show the existence of more compact and closed pore structures. The modification of the structure of the biosorbents i.e. more compact and closed pore structures is a clear indication of $\mathrm{Cr}(\mathrm{VI})$ sequestration.

The results of the FTIR analysis performed on the biosorbent materials before and after the biosorption process are shown in Figure 2. The broad bands around 3400/cm detected in both biomaterials can be attributed to $-\mathrm{OH}$ and-NH stretching vibrations of hydroxyl groups while peaks assigned to alkyl-C-H stretching are observed around 2900/cm [26]. Peaks around $2100 / \mathrm{cm}$ and $1600 / \mathrm{cm}$ are due to $-\mathrm{C} \equiv \mathrm{N}$ and $-\mathrm{NHCO}$ stretching, respectively [42]. This demonstrates that after chemical activation, many amine groups were embedded onto the CMOS and CM-DP surfaces.

The quantification surface analysis of fresh CM-OS and CM-DP was performed using XPS. The survey scans of these samples showed the existence of carbon, oxygen, nitrogen, sulphur and silicon (see Table 1). Two peaks corresponding to pyrrolic-N (399.9 eV) and quaternary-N (402.0eV) were observed [42]. The amine groups introduced on the surface will promote the removal of $\mathrm{Cr}(\mathrm{VI})$ anions. The high-resolution spectra collected from the fresh and 
Cr loaded CM-OS and CM-DP is shown in Figure 3. By relating the $\mathrm{Cr}$ peaks revealed, it is feasible to determine whether the bound $\mathrm{Cr}$ is in trivalent or hexavalent form. From Figure 3 it can be established that $\mathrm{Cr}(\mathrm{VI})$ was almost completely reduced to $\mathrm{Cr}$ (III) when brought into contact with the CM-OS and CM-DP. This proves that the removal mechanism of Cr(VI) by CM-OS and CM-DP involves three steps i) attraction of $\mathrm{Cr}(\mathrm{VI})$ ions to positively charged groups such as- $\mathrm{CN}^{+}$; ii) reduction of $\mathrm{Cr}(\mathrm{VI})$ to $\mathrm{Cr}(\mathrm{III})$ by neighbouring electron-donor groups such as-SiOH; iii) $\mathrm{Cr}$ (III) ions are adsorbed through metal ion coordination, ion exchange and chelating activities.

\subsection{Effect of pH}

The solution $\mathrm{pH}$ was found to have a significant influence on the $\mathrm{Cr}(\mathrm{VI})$ removal by CM-OS and CM-DP, which is illustrated in Figure 4. The acidic condition $(\mathrm{pH}=2)$ was more favourable for the $\mathrm{Cr}(\mathrm{VI})$ biosorption by both CM-OS and CM-DP and had a maximum uptake of 22.7 and $30.5 \mathrm{mg} / \mathrm{g}$ and percentage removal of $56.7 \%$ and $76.24 \%$ by CM-DP and CM-OS, respectively. As solution $\mathrm{pH}$ increased, the biosorption capacity of $\mathrm{Cr}(\mathrm{VI})$ decreased. Albadarin et al. using date pit and tea waste [26] and Kurniawan et al. using coconut shell charcoal [22] also reported the same observation.

In comparison to the raw materials, activated biomasses will have higher ability to reduce $\mathrm{Cr}(\mathrm{VI})$ to $\mathrm{Cr}$ (III) in industrial wastewaters, as the amino groups from epichlorohydrin and DETA can easily protonate the material surface in acid medium, improving the adsorption of $\mathrm{Cr}(\mathrm{VI})$ through ion exchange and electrostatic interaction [25]. When $\mathrm{pH}$ is low, $\mathrm{Cr}(\mathrm{VI})$ is reduced to $\mathrm{Cr}$ (III) due to its contact with electron donor group of the activated biosorbents [13, 43]. It may be indicated that the complexation mechanisms can be dominant in the biosorption system of the biosorbents and $\mathrm{Cr}(\mathrm{VI})$ [11]. The change of the colour of the biosorbents and the solution from orange to light green indicated the presence of $\mathrm{Cr}(\mathrm{III})$ and reduction of $\mathrm{Cr}(\mathrm{VI})$ to $\mathrm{Cr}(\mathrm{III})$ as $\mathrm{Cr}(\mathrm{III})$ did not exist in the initial solution.

$\mathrm{Cr}(\mathrm{III})$ is detected in the aqueous solution due to the electrostatic repulsion between $\mathrm{Cr}$ (III) and positively charged CM-DP and CM-OS surface at low $\mathrm{pH}$. As $\mathrm{Cr}$ (III) formed because of reduction it can be adsorbed at $\mathrm{pH}$ above the PZC because the negatively charged CM-DP and CM-OS surface. When $\mathrm{pH}$ is above 2 , hydrogen chromate $\left(\mathrm{HCrO}^{4-}\right)$ was lower, and thus the biosorption-coupled reduction of $\mathrm{Cr}(\mathrm{VI})$ to $\mathrm{Cr}(\mathrm{III})$ was less. It was reported that when functional groups such as the carboxyl groups are formed, it can yield new ion-exchange sites for reduced $\mathrm{Cr}(\mathrm{III})$ and increase the biosorption capacity effectively [44].

At $\mathrm{pH}=2$, the main form of $\mathrm{Cr}(\mathrm{VI})$ is the negatively charged hydrogen chromate 
$\left(\mathrm{HCrO}^{4-}\right)$ which is electrostatically attracted to the positively charged CM-DP and CM-OS [43]. The possible reason for lower biosorption at higher $\mathrm{pH}$ is that excess amount of hydroxide ion $\left(\mathrm{OH}^{-}\right)$competes with the negatively charged $\mathrm{Cr}(\mathrm{VI})$ ions. When $\mathrm{pH}$ range is 3 to 5 , the removal was $10 \%$ to $50 \%$. This can be an indication of possible involvement of other metal attachment such as coagulation or precipitation when $\mathrm{pH}$ is higher than 3 [1].

\subsection{Effect of activated biosorbents dosage}

The effect of biosorbent dosage on the biosorption of Cr(VI) by CM-OS and CM-DP was studied. As illustrated in Figure 5, when the biosorbent dosage increased, the removal increased. For CM-DP, the maximum Cr(VI) removal was $96.83 \%$ and could be achieved when the biosorbent dosage was $11 \mathrm{~g} / \mathrm{L}$. For CM-OS, the maximum $\mathrm{Cr}(\mathrm{VI})$ removal was $95.25 \%$ and could be achieved when the biosorbent dosage was $10 \mathrm{~g} / \mathrm{L}$. Similar results were reported in [26] which showed a removal of $96.8 \%$ at the CM-DP dosage $10 \mathrm{~g} / \mathrm{L}$. When the biosorbent mass increases, the availability of surface area of the biosorbent is higher, leading to the higher removal of $\mathrm{Cr}(\mathrm{VI})$. The observed decrease in the concentration of $\mathrm{Cr}(\mathrm{VI})$ in solid phase; $q_{\mathrm{e}}$, is that at higher dosage there is still removal for adsorption of more chromium ions due to the presence of more active sites for adsorption [1].

\subsection{Effect of initial concentration}

The effect of initial concentration, in the range of 10-200 ppm, on the biosorption of $\mathrm{Cr}(\mathrm{VI})$ on CM-OS and CM-DP was studied. The result showed that $\mathrm{Cr}(\mathrm{VI})$ removal depends significantly on the initial concentration of $\mathrm{Cr}(\mathrm{VI})$ as illustrated in Figure 6. When the initial concentration of $\mathrm{Cr}(\mathrm{VI})$ increased the remaining concentration of $\mathrm{Cr}(\mathrm{VI})$ in the aqueous solution increased. The concentration of $\mathrm{Cr}$ (III) ions in solution also increased for both activated biosorbent materials. At higher initial concentrations of $\mathrm{Cr}(\mathrm{VI})$ there is more competition for actives sites for the reduction and removal of both species of chromium ions from solution. This result is in agreement with other reports in literature [2, 3, 45]. The results show that CM-OS has a greater potential for reduction of $\mathrm{Cr}$ (VI) to $\mathrm{Cr}$ (III) and uptake of $\mathrm{Cr}$ (III) at higher initial concentrations of $\mathrm{Cr}(\mathrm{VI})$.

\subsection{Biosorption isotherms}

The summary of the parameters for the different isotherms obtained from non-linear regression in Sigma Plot v.11 (Systat Software Inc., US) are reported in Table 1 : XPS elemental analysis of fresh and Cr loaded CM-DP and CM-OS 


\begin{tabular}{l|llllll}
\hline Material & Elements & & & & \\
& O 1s & C 1s & N 1s & S 1s & Si 1s & Cr 2p \\
\hline CM-OS & $21.81 \%$ & $76.25 \%$ & $1.37 \%$ & $0.32 \%$ & $0.25 \%$ & - \\
CM-DP & $20.42 \%$ & $77.75 \%$ & $1.22 \%$ & $0.33 \%$ & $0.28 \%$ & - \\
Cr onto CM-DP & $23.17 \%$ & $74.34 \%$ & $1.33 \%$ & $0.37 \%$ & $0.24 \%$ & $0.55 \%$ \\
Cr onto CM-OS & $22.11 \%$ & $76.48 \%$ & $1.19 \%$ & $0.34 \%$ & $0.22 \%$ & $0.34 \%$ \\
\hline
\end{tabular}

Table 2. By comparing the statistical parameters of the models, for CM-DP, the best model fitting the experimental data is the Freundlich model, followed by the Toth, RedlichPeterson, Khan, Langmuir and then Dubinin-Radushkevich model, while for CM-OS, the Toth model and the Freundlich model are best to fit the experimental data, followed by DubininRadushkevich, Redlich-Peterson, Khan and Langmuir model. This indicates a indicating heterogeneous biosorption systems. The constants of each isotherm model, correlation coefficients $\left(\mathrm{R}^{2}\right)$, mean relative error (MRE) and standard error of estimate (SEE) of the date pit and olive stone are given in Table 2. Comparison of the experimental data for the $q_{\mathrm{e}}$ values and fits of the Freundlich model are shown in Figure 6.

\subsection{Comparison of performance with other low-cost materials for $\mathrm{Cr}$ removal}

The performance of CM-DP and CM-OS was compared with other materials found in literature and the results are shown in Table 3. It is clear from Table 3 that both CM-DP and CM-OS are viable biosorbent materials for the removal for $\mathrm{Cr}(\mathrm{VI})$.

\subsection{Effect of ionic strength}

The wastewater from industry may contain other ions in addition to the chromium ions. The increase of ionic strength can lead to an increase of the Debye-Huckel screening influence and, accordingly, to a decrease of the electrostatic interaction between biosorption sites and adsorbate. Thus, the effect of ionic strength on the $\mathrm{Cr}(\mathrm{VI})$ was studied as shown in Figure 7 using sodium chloride $(\mathrm{NaCl})$.

The $\mathrm{Cr}(\mathrm{VI})$ removal decreased as the concentration of $\mathrm{NaCl}$ increased. Similar observations were obtained by Albadarin et al., [26]. In their works, the decrease in the biosorption capacity $q_{\mathrm{e}}$ was relatively slight, in the range of 0.3 to $0.4 \mathrm{mmol} / \mathrm{g}$ for date pit. This can be due to different initial conditions used for this experiment. Other works using other adsorbents had similar observations [1]. It is reported that as the ionic strength of the aqueous 
solution increases, the biosorption capacity of $\mathrm{Cr}(\mathrm{VI})$ decreases [46]. When the ionic strength is higher, the $\mathrm{Cr}(\mathrm{VI})$ uptake may decrease because of competition for biosorption active sites between chromate and chloride anions.

In general, ionic strength influences the ion exchange sorption mechanisms and $\mathrm{pH}$ affects surface complexation mechanisms. The biosorption extent of $\mathrm{Cr}(\mathrm{VI})$ by the biomass did not decrease significantly with the increase of the concentration of $\mathrm{NaCl}$, possibly because the predominant biosorption type is chemisorption other than physical sorption; in other words, surface complexation rather than ion exchange. There must be particular interactions, rather than simple electrostatic interactions, between $\mathrm{Cr}$ in hexavalent and trivalent form and their surface binding sites [1, 26, 47].

\subsection{Effect of co-existing ions}

Since different kinds of foreign ions such as $\mathrm{NH}^{4+}$ and $\mathrm{Na}^{+}$can also be found in the industrial effluent, which can have an effect on the $\mathrm{Cr}(\mathrm{VI})$ uptake, the influences of various salts, such as $\mathrm{NaCl}, \mathrm{NH}_{4} \mathrm{Cl}, \mathrm{K}_{2} \mathrm{SO}_{4}, \mathrm{NaNO}_{3}, \mathrm{NaHCO}_{3}$, on the biosorption of $\mathrm{Cr}(\mathrm{VI})$ onto date pit and olive stone were studied. It was found that the Cr(VI) removal onto CM-DP and CMOS decreased greatly in the presence of the $\mathrm{NaHCO}_{3}$ salt, which may indicate that carbonate ions $\left(\mathrm{CO}_{3}{ }^{2-}\right)$ strongly compete with $\mathrm{Cr}(\mathrm{VI})$ for the binding sites (Figure 8). Moreover, the $\mathrm{Cr}(\mathrm{VI})$ removal onto CM-DP and CM-OS decreased with the presence of other salts, which can be due to the weak interaction between the negative and positive charge, leading to limitation of the attraction between the biomass particles and $\mathrm{Cr}(\mathrm{VI})$ ions. The result was similar to the other works $[1-3,26]$.

\subsection{Biosorption kinetics}

The influence of the temperature was studied at room temperature $\left(20^{\circ} \mathrm{C}\right), 30^{\circ} \mathrm{C}, 40{ }^{\circ} \mathrm{C}$ and $50{ }^{\circ} \mathrm{C}$ at solution $\mathrm{pH} 2$ with an initial $\mathrm{Cr}(\mathrm{VI})$ concentration $100 \mathrm{ppm}$ and dosage $2.5 \mathrm{~g} / \mathrm{L}$, on hot plates for 360min. At chosen time intervals, certain volumes of samples are withdrawn and analysed of the concentration. As illustrated in Figure 10 the result showed that the initial rate of biosorption was high during the first 4 for CM-DP and 1 hours CM-OS, then decreased gradually to 0 reaching the maximum amount adsorbed. Similar results were obtained by other works $[2,26]$. The reason can be that at the start of the process, there are many sites available for chromate ions to be occupied and, after all the sites are taken, the surface of biosorbent is inadequate and the controlling rate is the rate of transport from the external sites to the interior biosorbent particles. 
The other reason may be that the driving force of the biosorption, which is $\left(q_{\mathrm{e}}-q_{\mathrm{t}}\right)$ and assumed in the derivation of the pseudo reaction kinetic models, decreases [1, 14]. Moreover, with the increase of solution temperature, the equilibrium biosorption capacity increased for the CM-DP and decreased for the CM-OS, indicating that the process of CM-DP biosorption is endothermic, which is the same result as reported by Albadarin et al., [26] and the CM-OS biosorption process is exothermic. The reduction of the $\mathrm{Cr}(\mathrm{VI})$ to $\mathrm{Cr}(\mathrm{III})$ is spontaneous. When the temperature of the solution is higher, it is possible for the $\mathrm{Cr}$ (III) to have loss of some hydration spheres and diffusion into the smaller channels toward the biosorption sites with less accessibility $[26,48]$. The mechanisms investigations of the biosorption shows that the ionexchange is not the predominant mechanism of $\mathrm{Cr}(\mathrm{VI})$ for the biomass.

When $\mathrm{Cr}(\mathrm{VI})$ is completely reduced to $\mathrm{Cr}(\mathrm{III})$, there is a possibility that $\mathrm{Cr}$ (III) metal cation substitutes for some alkaline earth metals existing in the cell wall. Because the binding is coordinative and the electrostatic attraction between the negatively charged groups in the biomass and metal ions becomes stronger, the nature of the cross-linking may be changed [26, 49]. The kinetic studies also showed that the biosorption of $\mathrm{Cr}(\mathrm{VI})$ onto CM-DP has a twophase process which includes the rapid reduction of $\mathrm{Cr}(\mathrm{VI})$ to $\mathrm{Cr}(\mathrm{III})$ followed by biosorption [6]. The kinetic data is used to determinate of the rate of $\mathrm{Cr}(\mathrm{VI})$ uptake or reduction to $\mathrm{Cr}$ (III) and the time required to reach equilibrium [1]. To study the kinetics of the biosorption process, the pseudo first and pseudo second reaction kinetic model were considered to describe the result of the experiment. The values of the constants of the two kinetic models, their biosorption capacity and correlation coefficients of the date pit and olive stone are given in Table 4. Nonlinear regression fits of the pseudo second order equation at different temperatures demonstrated a good agreement of linear relationship with the experimental result with high correlation coefficient $\mathrm{R}^{2}>0.95$ for CM-DP as well as CM-OS, compared with the plot of the pseudo first order with low correlation coefficient $\mathrm{R}^{2}<0.90$ for CM-DP and $\mathrm{R}^{2}<0.30$ for CMOS (see Figure 9).

Thus, the pseudo second order model best describe the biosorption of chromium onto CM-DP and CM-OS. The assumption of this model is that the process of biosorption has two steps. The first step occurs fast and achieves equilibrium quickly, and the second step takes place slowly and can last for a long time $[1,23]$. Second order model is known to describe best chemisorption controlled rate-limiting mechanisms including valence forces through share/exchange of electrons between sorbent and adsorbate. However, this must be confirmed using various analytical techniques and tests.

To check if the sorption process is diffusion controlled, intraparticle diffusion and Boyd 
models were also applied $[1,31,50]$. The kinetic constants and the correlation coefficients of the intraparticle diffusion model at various temperature are shown in Table 5.

The $t^{0.5}$ versus $q_{\mathrm{t}}$ plots were non-linear and did not pass through the origin which may be an indication intraparticle diffusion was not the only rate limiting process for the biosorption process. The plots had two linear segments; the first segment is attributed to the mass transfer of the adsorbent on the exterior surface of the adsorbent and the second segment is attributed to diffusion of the adsorbate into interior pores of the sorbent material $[1,10]$.

The Boyd model was used to determine whether the rate determining step in mass transfer was particle diffusion, which is the diffusion within the pores, or the film diffusion, which is the boundary layer. As shown in (Table 4) the correlation coefficients at each temperature were low $\left(\mathrm{R}^{2}<0.900\right)$, which means that the plots were not linear, and the plot also did not pass through the origin. This indicated that the rate-controlling step might be the film diffusion. When the ion-exchange is the mechanism of the biosorption, the rate-limiting step can be liquid film diffusion or particle diffusion. In general, external transport is considered to be the ratelimiting biosorption process $[1,51]$. The reason for the strong external resistance might be the inadequate mixing, dilute concentration of adsorbate and small particle size of the CM-DP and CM-OS. Therefore, the film diffusion may greatly restrict the intraparticle step with the highest resistance and it might be the predominant and control step for the overall biosorption rate [1, 18]. Similar results and conclusions were obtained from studies on removal of $\mathrm{Cr}(\mathrm{VI})$ using other adsorbents $[1,3]$.

\subsection{Thermodynamic parameters}

Table 5 shows the estimated thermodynamic parameters; change in enthalpy $(\Delta \mathrm{H})$, change in free Gibbs energy $(\Delta \mathrm{G})$ and change in entropy $(\Delta \mathrm{S})$ for the biosorption of $\operatorname{Cr}(\mathrm{VI})$ onto CM-OS and CM-DP. Positive values of $\Delta \mathrm{G}$ and $\Delta \mathrm{S}$ and $\Delta \mathrm{H}$ for $\mathrm{Cr}(\mathrm{VI})$ biosorption onto CM-OS indicate that the biosorption process is non-spontaneous and exothermic. The increase in temperature increased the values of $\Delta \mathrm{G}^{\circ}$ showing that the biosorption process is less spontaneous at a high temperature.

On the other hand, the positive $\Delta \mathrm{H}^{\circ}$ value for $\mathrm{Cr}(\mathrm{VI})$ biosorption onto CM-DP indicates that the process is endothermic, and the reaction becomes more spontaneous at higher temperature. It can also be noted that the energies involved in the process $(\approx 13 \mathrm{~kJ} / \mathrm{mol})$ are within the range of the intermolecular interactions characteristic binding energy of chemical bonding and electrostatic attractions $(6-80 \mathrm{~kJ} / \mathrm{mol})$. 


\section{Conclusions}

It can be concluded the chemical modified date pit and chemical modified olive stone are both viable materials for the removal of $\mathrm{Cr}(\mathrm{VI})$ through reduction and biosorption. The chemical modification of material helps increase the biosorption capacity of biosorbents. This can be attributed to the additional functional groups which are introduced by chemical modification. The removal mechanism of hexavalent chromium is through reduction of the $\mathrm{Cr}(\mathrm{VI})$ on the surface of the biosorbent materials followed by biosorption of the $\mathrm{Cr}$ (III) ions. Presence of other competing ions in solution also affect the removal of $\mathrm{Cr}(\mathrm{VI})$ from solution as previously reported. Further studies on re-use of these materials will be evaluated in our next study.

\section{References}

1. Albadarin, A.B., et al., Biosorption of toxic chromium from aqueous phase by lignin: mechanism, effect of other metal ions and salts. Chemical Engineering Journal, 2011. 169(1-3): p. 20-30.

2. Albadarin, A.B., et al., Novel comparison of kinetic models for the adsorption-coupled reduction of Cr(VI) using untreated date pit biomaterial. Ecological Engineering, 2014. 70: p. 200-205.

3. Albadarin, A.B., et al., Retention of toxic chromium from aqueous phase by H3PO4-activated lignin: Effect of salts and desorption studies. Desalination, 2011. 274(1-3): p. 64-73.

4. Albadarin, A.B., et al., Modelling and Fixed Bed Column Adsorption of Cr(VI) onto Orthophosphoric Acid-activated Lignin. Chinese Journal of Chemical Engineering, 2012. 20(3): p. 469-477.

5. Dayan, A.D. and A.J. Paine, Mechanisms of chromium toxicity, carcinogenicity and allergenicity: Review of the literature from 1985 to 2000. Human \& Experimental Toxicology, 2001. 20(9): p. 439451.

6. EPA, Environmental Pollution Control Alternatives, PA/625/5-90/025, EPA/625/4-89/023, 1990, E.P. Agency: Cincinnati.

7. Rice, E.W., et al., Standard Methods for the Examination of Water and Wastewater. 2012: American Public Health Association, American Water Works Association, Water Environment Federation.

8. Fendorf, S.E., Surface reactions of chromium in soils and waters. Geoderma, 1995. 67(1): p. 55-71.

9. $\mathrm{Hu}, \mathrm{Z}$., et al., CO2 Capture in Metal-Organic Framework Adsorbents: An Engineering Perspective. Advanced Sustainable Systems, 2019. 3(1): p. 1800080.

10. Aguilar-Carrillo, J., et al., Sorption of As, Cd and Tl as influenced by industrial by-products applied to an acidic soil: Equilibrium and kinetic experiments. Chemosphere, 2006. 65(11): p. 2377-2387.

11. Bai, R.S. and T.E. Abraham, Studies on enhancement of $\mathrm{Cr}(\mathrm{VI})$ biosorption by chemically modified biomass of Rhizopus nigricans. Water Research, 2002. 36(5): p. 1224-1236.

12. El Nemr, A., et al., Treatment of wastewater containing toxic chromium using new activated carbon developed from date palm seed. Journal of Hazardous Materials, 2008. 152(1): p. 263-275.

13. Gardea-Torresdey, J.L., et al., Characterization of $\mathrm{Cr}$ (VI) binding and reduction to $\mathrm{Cr}$ (III) by the agricultural byproducts of Avena monida (Oat) biomass. Journal of Hazardous Materials, 2000. 80(13): p. 175-188.

14. Kaminski, W., E. Tomczak, and K. Jaros, Interactions of metal ions sorbed on chitosan beads. Desalination, 2008. 218(1-3): p. 281-286.

15. Liu, X., et al., Adsorption of heavy metal ion from aqueous single metal solution by aminated epoxylignin. BioResources, 2013. 8(2): p. 2257-2269.

16. Martín-Lara, M., et al., Sorption of $\mathrm{Cr}$ (VI) onto Olive Stone in a Packed Bed Column: Prediction of Kinetic Parameters and Breakthrough Curves. Journal of Environmental Engineering, 2010. 136(12): p. 1389-1397.

17. Mckay, G., H. Blair, and A. Findon. Sorption of metal ions by chitosan. in Proc. Conf. Immobilisation of 
Ions by BiosorptionSoc. Chem. Ind., Lancaster University. 1986.

18. Mohan, D., et al., Kinetics of mercury adsorption from wastewater using activated carbon derived from fertilizer waste. Colloids and Surfaces A: Physicochemical and Engineering Aspects, 2001. 177(23): p. 169-181.

19. Olalekan, A., A. Dada, and A. Okewale, Comparative Adsorption Isotherm Study of the Removal of Pb2+ and Zn2+ Onto Agricultural Waste. 2013.

20. Prabhakaran, S.K., K. Vijayaraghavan, and R. Balasubramanian, Removal of Cr(VI) lons by Spent Tea and Coffee Dusts: Reduction to Cr(III) and Biosorption. Industrial \& Engineering Chemistry Research, 2009. 48(4): p. 2113-2117.

21. Foo, K.Y. and B.H. Hameed, Insights into the modeling of adsorption isotherm systems. Chemical Engineering Journal, 2010. 156(1): p. 2-10.

22. Blázquez, G., et al., The effect of $\mathrm{pH}$ on the biosorption of $\mathrm{Cr}$ (III) and $\mathrm{Cr}$ (VI) with olive stone. Chemical Engineering Journal, 2009. 148(2-3): p. 473-479.

23. Kula, I., et al., Adsorption of Cd(II) ions from aqueous solutions using activated carbon prepared from olive stone by ZnCl2 activation. Bioresource Technology, 2008. 99(3): p. 492-501.

24. Srivastava, S., S. Agrawal, and M. Mondal, Biosorption isotherms and kinetics on removal of $\mathrm{Cr}$ (VI) using native and chemically modified Lagerstroemia speciosa bark. Ecological Engineering, 2015. 85: p. 56-66.

25. Wang, K., et al., Removal of Chromium(VI) from Aqueous Solutions Using Fe304 Magnetic Polymer Microspheres Functionalized with Amino Groups. Materials, 2015. 8(12): p. 5461.

26. Albadarin, A.B., et al., Influence of solution chemistry on $\mathrm{Cr}(\mathrm{VI})$ reduction and complexation onto datepits/tea-waste biomaterials. Journal of Environmental Management, 2013. 114: p. 190-201.

27. Trujillo, M.C., et al., Simultaneous biosorption of methylene blue and trivalent chromium onto olive stone. Desalination and Water Treatment, 2016. 57(37): p. 17400-17410.

28. Nada, A.M., S.A. El-Mongy, and E.S.A. El-Sayed, Effect of different treatments on cellulose toward carboxylation and its applications for metal ion adsorption. 2008. Vol. 4. 2008.

29. Albadarin, A.B., et al., Biosorption characteristics of sawdust for the removal of Cd(II) ions: mechanism and thermodynamic studies. Chemical Engineering Transactions, 2011. 24: p. 1297-1302.

30. Benaïssa, H. Rate determining steps study in cadmium sorption from aqueous solutions by almond peel. in Eleventh International Water Technology Conference IWTC11 2007. Sharm El-Sheikh, Egypt.

31. Boyd, G.E., A.W. Adamson, and L.S. Myers, The Exchange Adsorption of Ions from Aqueous Solutions by Organic Zeolites. II. Kinetics1. Journal of the American Chemical Society, 1947. 69(11): p. 28362848.

32. Langmuir, I., The constitution and fundamental properties of solids and liquids,. Journal of the American Chemical Society, 1916. 38(11): p. 2221-2295.

33. Nguyen, C. and D.D. Do, The Dubinin-Radushkevich equation and the underlying microscopic adsorption description. Carbon, 2001. 39(9): p. 1327-1336.

34. Freundlich, H.M.F., Over the adsorption in solution. Journal of Physical Chemistry 1906. 57: p. 385471.

35. Redlich, O. and D.L. Peterson, A useful adsorption isotherm. Journal of Physical Chemistry, 1959. 63: p. 1024-1026.

36. Tóth, J., Uniform interpretation of gas/solid adsorption. Advances in Colloid and Interface Science, 1995. 55: p. 1-239.

37. Khan, A.R., R. Ataullah, and A. Al-Haddad, Equilibrium adsorption studies of some aromatic pollutants from dilute aqueous solutions on activated carbon at different temperatures. Journal Colloid Interface Science, 1997. 194: p. 154-165.

38. Dubinin, M.M. and L.V. Radushkevich. Equation of the characteristic curve of activated charcoal. in Proc. Acad. Sci. Phys. Chem. 1974. USSR.

39. Redlich, O. and D.L. Peterson, A Useful Adsorption Isotherm. The Journal of Physical Chemistry, 1959. 63(6): p. 1024-1024.

40. Toth, J., State equations of the solid gas interface layer. Acta Chem. Acad. Hung. , 1971. 69: p. 311317.

41. Khan, A.R., R. Ataullah, and A. Al-Haddad, Equilibrium Adsorption Studies of Some Aromatic Pollutants from Dilute Aqueous Solutions on Activated Carbon at Different Temperatures. Journal of Colloid and Interface Science, 1997. 194(1): p. 154-165.

42. Albadarin, A.B., et al., Single, simultaneous and consecutive biosorption of Cr(VI) and Orange II onto chemically modified masau stones. Journal of Environmental Management, 2017. 204: p. 365-374. 
43. Benefield, L.D., J.F. Judkins, and B.L. Weand, Process chemistry for water and wastewater treatment. 1982: Prentice-Hall.

44. Nakano, Y., K. Takeshita, and T. Tsutsumi, Adsorption mechanism of hexavalent chromium by redox within condensed-tannin gel. Water Research, 2001. 35(2): p. 496-500.

45. Rangabhashiyam, S. and N. Selvaraju, Evaluation of the biosorption potential of a novel Caryota urens inflorescence waste biomass for the removal of hexavalent chromium from aqueous solutions. Journal of the Taiwan Institute of Chemical Engineers, 2015. 47: p. 59-70.

46. Dönmez, G. and Z. Aksu, Removal of chromium(VI) from saline wastewaters by Dunaliella species. Process Biochemistry, 2002. 38(5): p. 751-762.

47. Wu, C.-H., Studies of the equilibrium and thermodynamics of the adsorption of Cu2+ onto as-produced and modified carbon nanotubes. Journal of Colloid and Interface Science, 2007. 311(2): p. 338-346.

48. Schneider, R.M., et al., Adsorption of chromium ions in activated carbon. Chemical Engineering Journal, 2007. 132(1-3): p. 355-362.

49. Murphy, V., et al., A novel study of hexavalent chromium detoxification by selected seaweed species using SEM-EDX and XPS analysis. Chemical Engineering Journal, 2009. 148(2-3): p. 425-433.

50. Ho, Y.S. and G. McKay, Kinetic Models for the Sorption of Dye from Aqueous Solution by Wood. Process Safety and Environmental Protection, 1998. 76(2): p. 183-191.

51. Vadivelan, V. and K.V. Kumar, Equilibrium, kinetics, mechanism, and process design for the sorption of methylene blue onto rice husk. Journal of Colloid and Interface Science, 2005. 286(1): p. 90-100.

52. Malkoc, E., Y. Nuhoglu, and M. Dundar, Adsorption of chromium(VI) on pomace-An olive oil industry waste: Batch and column studies. Journal of Hazardous Materials, 2006. 138(1): p. 142-151.

53. Albadarin, A.B., et al., Experimental design and batch experiments for optimization of Cr(VI) removal from aqueous solutions by hydrous cerium oxide nanoparticles. Chemical Engineering Research and Design, 2014. 92(7): p. 1354-1362.

54. Soliman, M.A., G.M. Rashad, and M.R. Mahmoud, Development of the adsorption capability of MCM41 particles synthesized at room temperature using 8-hydroxyquinoline-5-sulfonic acid for removal of Co(II) and Cr(VI) in binary systems. Chemical Engineering Research and Design, 2019. 144: p. 459-471. 
Table 1:XPS elemental analysis of fresh and Cr loaded CM-DP and CM-OS

\begin{tabular}{l|llllll}
\hline Material & $\begin{array}{l}\text { Elements } \\
\text { O 1s }\end{array}$ & C 1s & N 1s & S 1s & Si 1s & Cr 2p \\
\hline CM-OS & $21.81 \%$ & $76.25 \%$ & $1.37 \%$ & $0.32 \%$ & $0.25 \%$ & - \\
CM-DP & $20.42 \%$ & $77.75 \%$ & $1.22 \%$ & $0.33 \%$ & $0.28 \%$ & - \\
Cr onto CM-DP & $23.17 \%$ & $74.34 \%$ & $1.33 \%$ & $0.37 \%$ & $0.24 \%$ & $0.55 \%$ \\
Cr onto CM-OS & $22.11 \%$ & $76.48 \%$ & $1.19 \%$ & $0.34 \%$ & $0.22 \%$ & $0.34 \%$ \\
\hline
\end{tabular}

Table 2: The constants of each isotherm model, correlation coefficients $\left(R^{2}\right)$, mean relative error (MRE) and standard error of estimate (SEE) of the CM-OS and CM-DP. Experimental conditions: $\mathrm{pH}$ : 2; CM-OS $2.5 \mathrm{~g} / \mathrm{L}$ and room temperature.

\begin{tabular}{|c|c|c|c|c|c|c|c|}
\hline \multirow[b]{2}{*}{ Model } & \multicolumn{3}{|c|}{ Parameters } & \multirow[t]{2}{*}{ Model } & \multicolumn{3}{|c|}{ Parameters } \\
\hline & & $\begin{array}{l}\text { CM- } \\
\text { DP }\end{array}$ & $\begin{array}{l}\text { CM- } \\
\text { OS }\end{array}$ & & & $\begin{array}{l}\text { CM- } \\
\text { DP }\end{array}$ & $\begin{array}{c}\text { CM- } \\
\text { OS }\end{array}$ \\
\hline \multirow{5}{*}{ Langmuir } & $\mathrm{k}_{1}$ & 0.02 & 0.02 & \multirow{5}{*}{$\begin{array}{c}\text { Dubinin-- } \\
\text { Radushkevich }\end{array}$} & $\mathrm{q}_{\max }$ & 21.61 & 28.99 \\
\hline & $\mathrm{q}_{\mathrm{m}}$ & 53.31 & 82.63 & & $\mathrm{~K}_{\mathrm{DR}}$ & 0.02 & 0.03 \\
\hline & $\mathrm{R}^{2}$ & 0.93 & 0.88 & & $\mathrm{R}^{2}$ & 0.84 & 0.92 \\
\hline & $\operatorname{MRE}(\%)$ & 16.20 & 34.51 & & $\operatorname{MRE}(\%)$ & 30.42 & 22.74 \\
\hline & SEE & 1.58 & 2.40 & & SEE & 8.88 & 9.84 \\
\hline \multirow{6}{*}{ Freundlich } & $\mathrm{k}_{\mathrm{f}}$ & 2.12 & 1.85 & \multirow{6}{*}{$\begin{array}{l}\text { Redlich- } \\
\text { Peterson }\end{array}$} & $\mathrm{K}_{\mathrm{R}}$ & 1.13 & 1.17 \\
\hline & $1 / \mathrm{n}$ & 1.87 & 2.19 & & $a_{R}$ & 0.02 & 0.01 \\
\hline & $\mathrm{R}^{2}$ & 0.95 & 0.93 & & $\beta$ & 1.07 & 1.50 \\
\hline & $\operatorname{MRE}(\%)$ & 12.31 & 24.638 & & $\mathrm{R}^{2}$ & 0.94 & 0.91 \\
\hline & \multirow{2}{*}{ SEE } & \multirow{2}{*}{1.43} & \multirow{2}{*}{1.98} & & $\operatorname{MRE}(\%)$ & 15.20 & 28.41 \\
\hline & & & & & SEE & 1.81 & 2.23 \\
\hline \multirow{6}{*}{ Toth } & $\mathrm{K}_{\mathrm{t}}$ & 48.11 & 50.01 & \multirow{6}{*}{ Khan } & $\mathrm{q}_{\mathrm{s}} *(10)^{(3)}$ & 59.19 & 3.06 \\
\hline & $\mathrm{a}_{\mathrm{T}} 10^{(-4)}$ & 91.25 & 6.20 & & $b_{\mathrm{k}} *(10)^{(3)}$ & 0.02 & 0.41 \\
\hline & $\mathrm{g}$ & 1.19 & 2.87 & & $a_{k}$ & 1.06 & 23.62 \\
\hline & $\mathrm{R}^{2}$ & 0.94 & 0.93 & & $\mathrm{R}^{2}$ & 0.93 & 0.89 \\
\hline & $\operatorname{MRE}(\%)$ & 14.50 & 23.68 & & $\operatorname{MRE}(\%)$ & 18.87 & 30.57 \\
\hline & SEE & 1.79 & 2.01 & & SEE & 1.82 & 2.40 \\
\hline
\end{tabular}


Table 3: comparison of the biosorption capacities of the different materials from literature

\begin{tabular}{lcc}
\hline Biosorbent & Q $_{\max }(\mathbf{m g} / \mathbf{g})$ & Reference \\
\hline Olive industry waste & 10.80 & {$[52]$} \\
Spent Tea dust & 44.9 & {$[20]$} \\
Tea waste & 107.8 & {$[26]$} \\
Date pits & 96.02 & {$[26]$} \\
Modified masau stones & 94.32 & {$[42]$} \\
Olive stones & 4.99 & {$[16]$} \\
CM-DP & 53.31 & Current study \\
CM-OS & 82.63 & Current study \\
Hydrous Cerium Oxide & 43.1 & {$[53]$} \\
Nanoparticles & & {$[54]$} \\
HQS/MCM-41 & 69.7 & \\
\hline
\end{tabular}


Table 4: The biosorption kinetic model constants for Cr(VI) CM-DP and CM-OS at various temperature. Experimental conditions: initial Cr(VI) concentration:100 ppm; pH:2; dosage $2.5 \mathrm{~g} / \mathrm{L}$.

\begin{tabular}{|c|c|c|c|c|c|c|}
\hline \multirow{10}{*}{ CM-DP } & \multicolumn{2}{|c|}{ temperature $\left({ }^{\circ} \mathrm{C}\right)$} & 20 & 30 & 40 & 50 \\
\hline & \multirow{3}{*}{$\begin{array}{l}\text { pseudo } 1^{\text {st }} \\
\text { order }\end{array}$} & $\begin{array}{l}\mathrm{k}_{1} * 10^{3} \\
(1 / \mathrm{min})\end{array}$ & 16.30 & 10.30 & 12.30 & 10.80 \\
\hline & & $\mathrm{q}_{\mathrm{e}}(\mathrm{mg} / \mathrm{g})$ & 7.60 & 8.84 & 10.48 & 14.15 \\
\hline & & $\mathrm{R}^{2}$ & 0.79 & 0.51 & 0.73 & 0.88 \\
\hline & \multirow{3}{*}{$\begin{array}{l}\text { pseudo second } \\
\text { order }\end{array}$} & $\begin{array}{l}\mathrm{k}_{2} * 10^{4} \\
(1 / \mathrm{min})\end{array}$ & 38.77 & 31.02 & 26.25 & 17.54 \\
\hline & & $\mathrm{q}_{\mathrm{e}}(\mathrm{mg} / \mathrm{g})$ & 7.60 & 8.84 & 10.48 & 14.15 \\
\hline & & $\mathrm{R}^{2}$ & 0.97 & 0.95 & 0.95 & 0.97 \\
\hline & \multirow[t]{2}{*}{$\begin{array}{c}\text { intraparticle } \\
\text { diffusion }\end{array}$} & $\begin{array}{c}\mathrm{k}_{\text {diff }} \\
\left(\mathrm{mg} / \mathrm{g} \min ^{0.5}\right)\end{array}$ & 0.72 & 1.63 & 1.47 & 1.38 \\
\hline & & $\mathrm{R}^{2}$ & 0.73 & 0.64 & 0.84 & 0.89 \\
\hline & Boyd model & $\mathrm{R}^{2}$ & 0.84 & 0.73 & 0.79 & 0.93 \\
\hline \multirow{9}{*}{ CM-OS } & \multirow{3}{*}{$\begin{array}{l}\text { pseudo } 1^{\text {st }} \\
\text { order }\end{array}$} & $\begin{array}{l}\mathrm{k}_{1} * 10^{3} \\
(1 / \mathrm{min})\end{array}$ & 15.00 & 10.60 & 24.80 & 11.00 \\
\hline & & $\mathrm{q}_{\mathrm{e}}(\mathrm{mg} / \mathrm{g})$ & 23.41 & 25.01 & 18.81 & 13.16 \\
\hline & & $\mathrm{R}^{2}$ & -0.76 & 0.14 & 0.29 & -0.52 \\
\hline & \multirow{3}{*}{$\begin{array}{l}\text { pseudo 2nd } \\
\text { order }\end{array}$} & $\begin{array}{l}\mathrm{k}_{2} * 10^{4} \\
(1 / \mathrm{min})\end{array}$ & 45.97 & 20.87 & 54.64 & 111.59 \\
\hline & & $\mathrm{q}_{\mathrm{e}}(\mathrm{mg} / \mathrm{g})$ & 23.41 & 25.01 & 18.81 & 13.16 \\
\hline & & $\mathrm{R}^{2}$ & 0.99 & 0.99 & 0.99 & 0.98 \\
\hline & \multirow[t]{2}{*}{$\begin{array}{l}\text { intraparticle } \\
\text { diffusion }\end{array}$} & $\begin{array}{c}\mathrm{k}_{\text {diff }} \\
\left(\mathrm{mg} / \mathrm{g} \min ^{0.5}\right)\end{array}$ & 3.85 & 2.75 & 2.93 & 1.85 \\
\hline & & $\mathrm{R}^{2}$ & 0.83 & 0.85 & 0.92 & 0.92 \\
\hline & Boyd model & $\mathrm{R}^{2}$ & 0.70 & 0.90 & 0.71 & 0.69 \\
\hline
\end{tabular}


Table 5 thermodynamic parameters

\begin{tabular}{|l|l|l|l|c|c|c|}
\hline Material & \multirow{2}{*}{$\Delta \mathrm{H}(\mathrm{kJ} / \mathrm{mol})$} & $\Delta \mathrm{S}(\mathrm{J} / \mathrm{mol} \mathrm{K})$ & \multicolumn{4}{|c|}{$\Delta \mathrm{G}(\mathrm{kJ} / \mathrm{mol})$} \\
\cline { 3 - 7 } & & & $20^{\circ} \mathrm{C}$ & $30^{\circ} \mathrm{C}$ & $40^{\circ} \mathrm{C}$ & $50^{\circ} \mathrm{C}$ \\
\hline CM-OS & -20.72 & -71.31 & 0.180 & 0.892 & 1.606 & 2.319 \\
& & & & & & \\
\hline CM-DP & 21.67 & 64.21 & 2.913 & 2.206 & 1.564 & 0.922 \\
& & & & & & \\
\hline
\end{tabular}



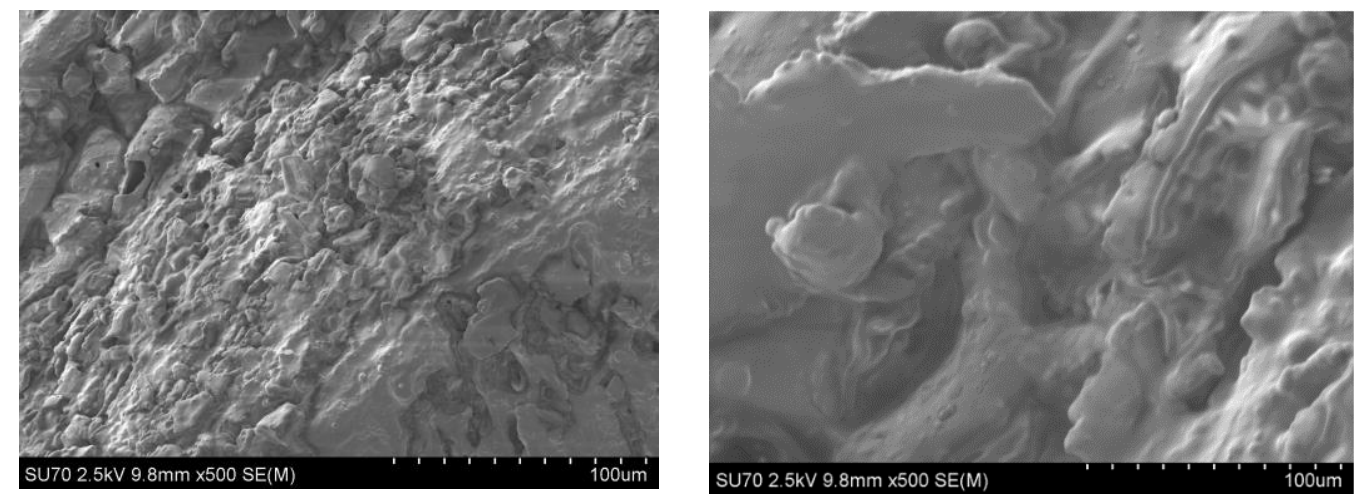

(a)- CM-DP before biosorption

(b) CM-DP after biosorption

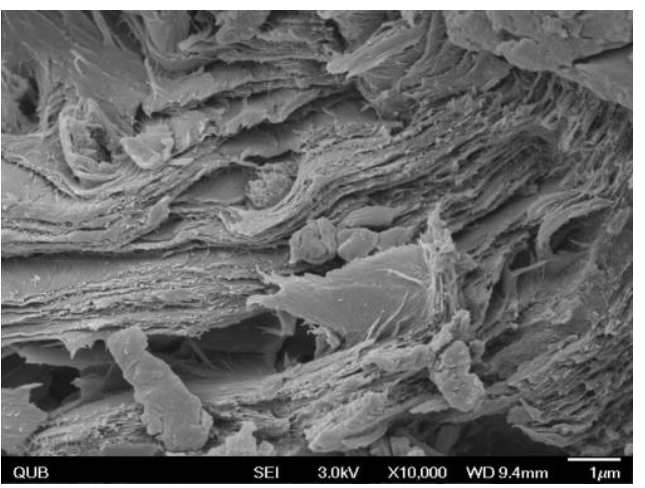

(c) CM-OS before biosorption

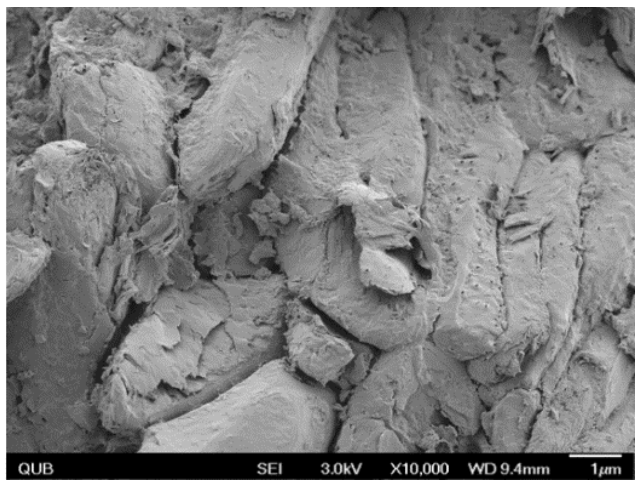

(d) CM-DP after biosorption

Figure 1: SEM of the biosorbents before and after biosorption. 
(a)

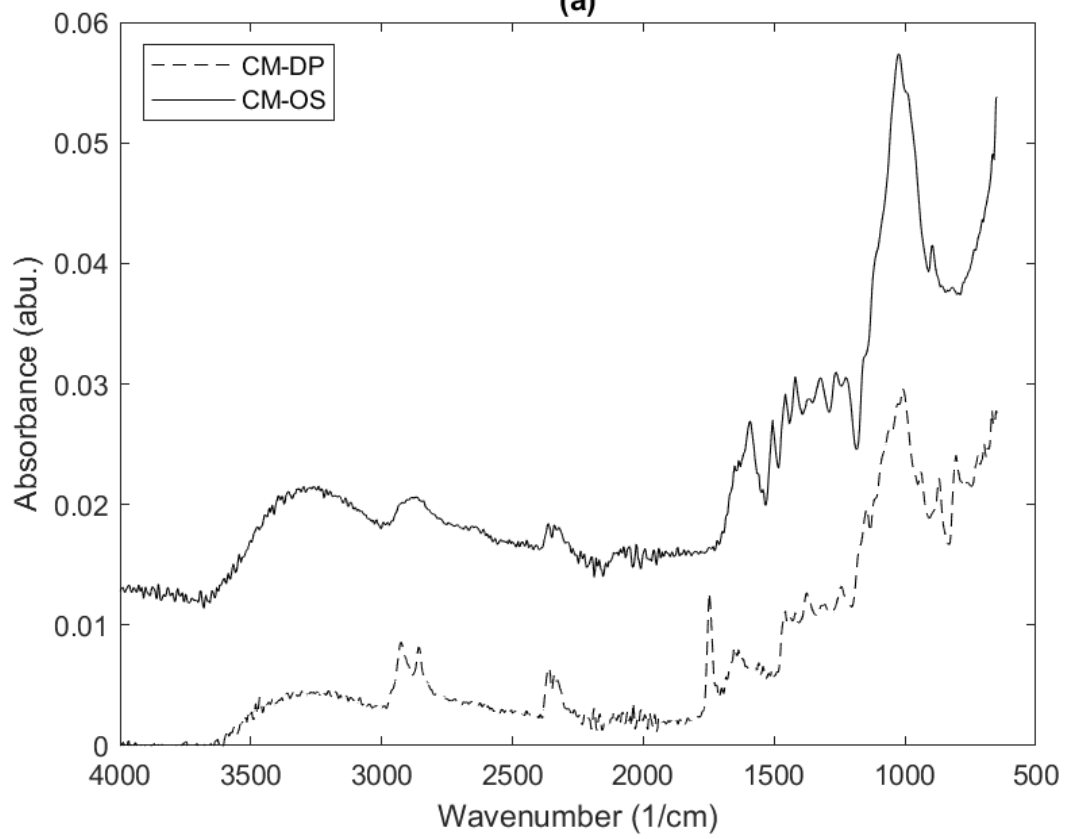

(b)

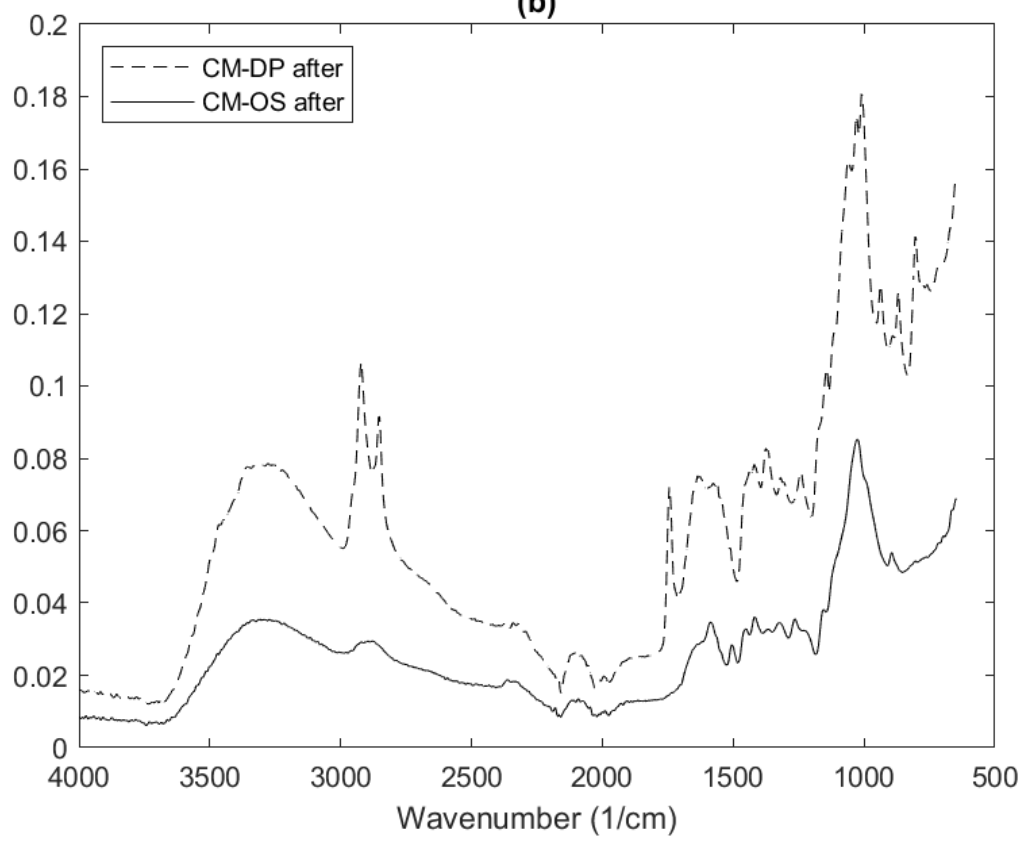

Figure 2: FTIR spectra of the samples before (a) and after (b) contacting with chromium (VI) solutions. 


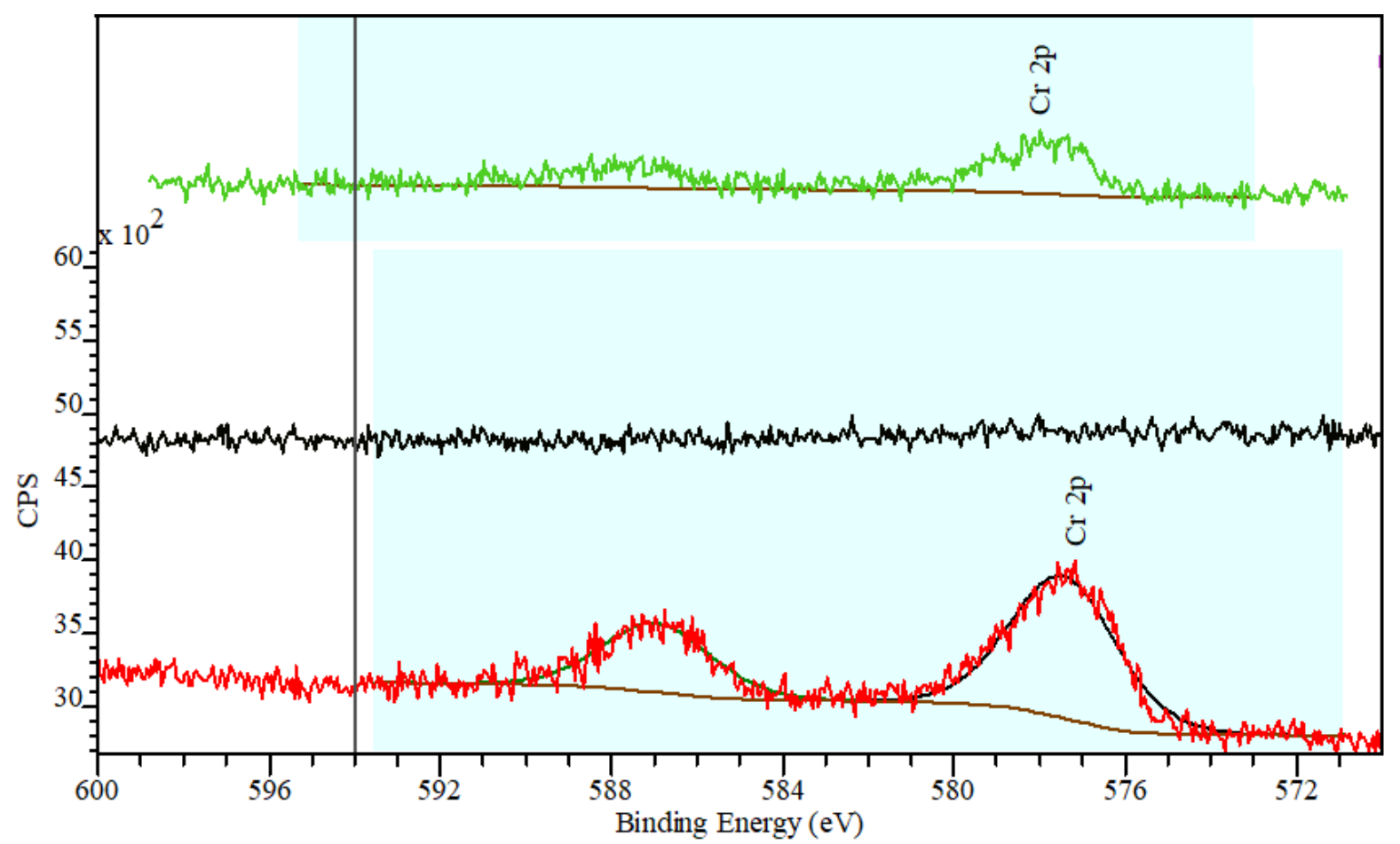

Figure 3: XPS spectra of fresh and Cr(VI) loaded CM-OS and CM-DP. 

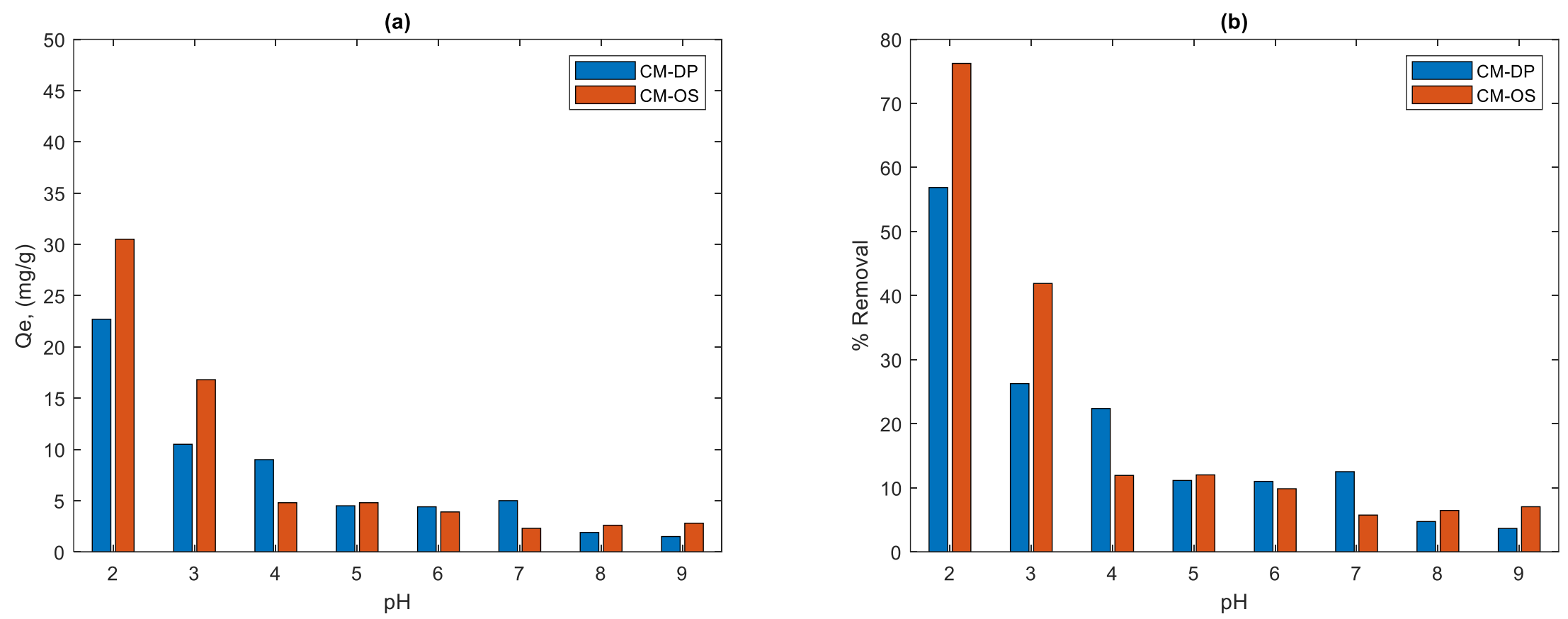

Figure 4: Effect of $\mathrm{pH}$ on the removal of Cr(IV) from solution using CM-PD and CM_OS, initial concentration $100 \mathrm{ppm}$, dosage $1.0 \mathrm{~g} / \mathrm{L}$. 
(a)

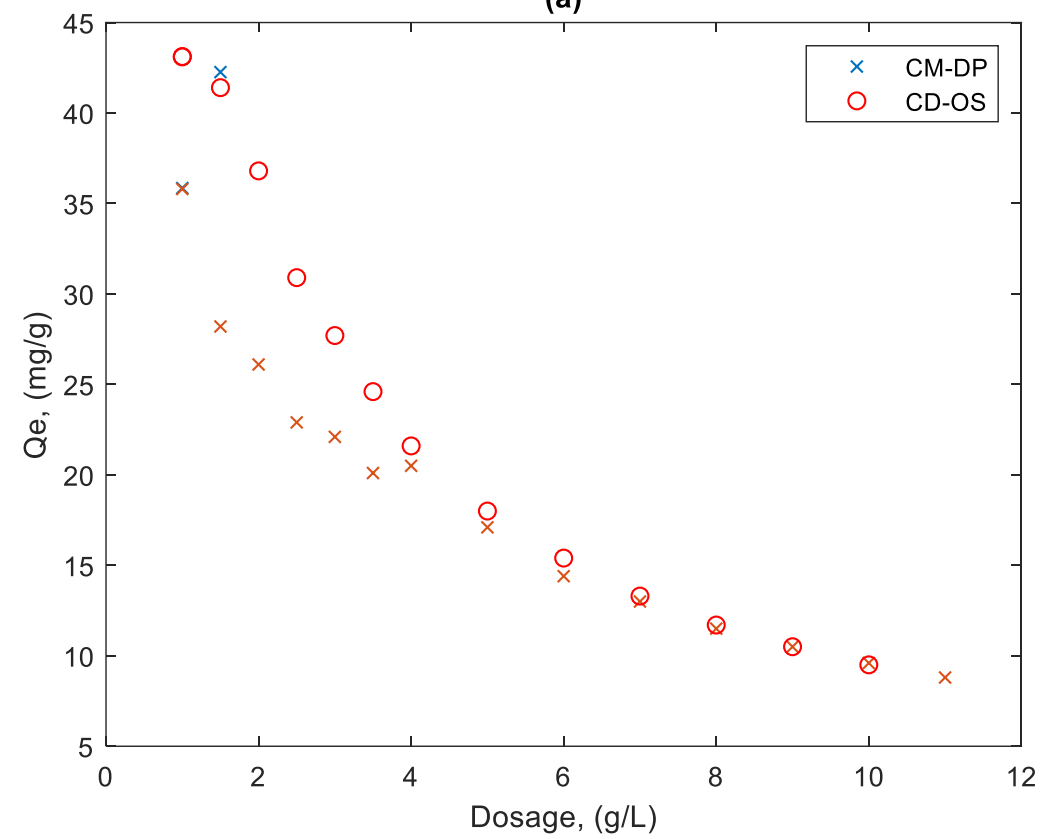

(b)

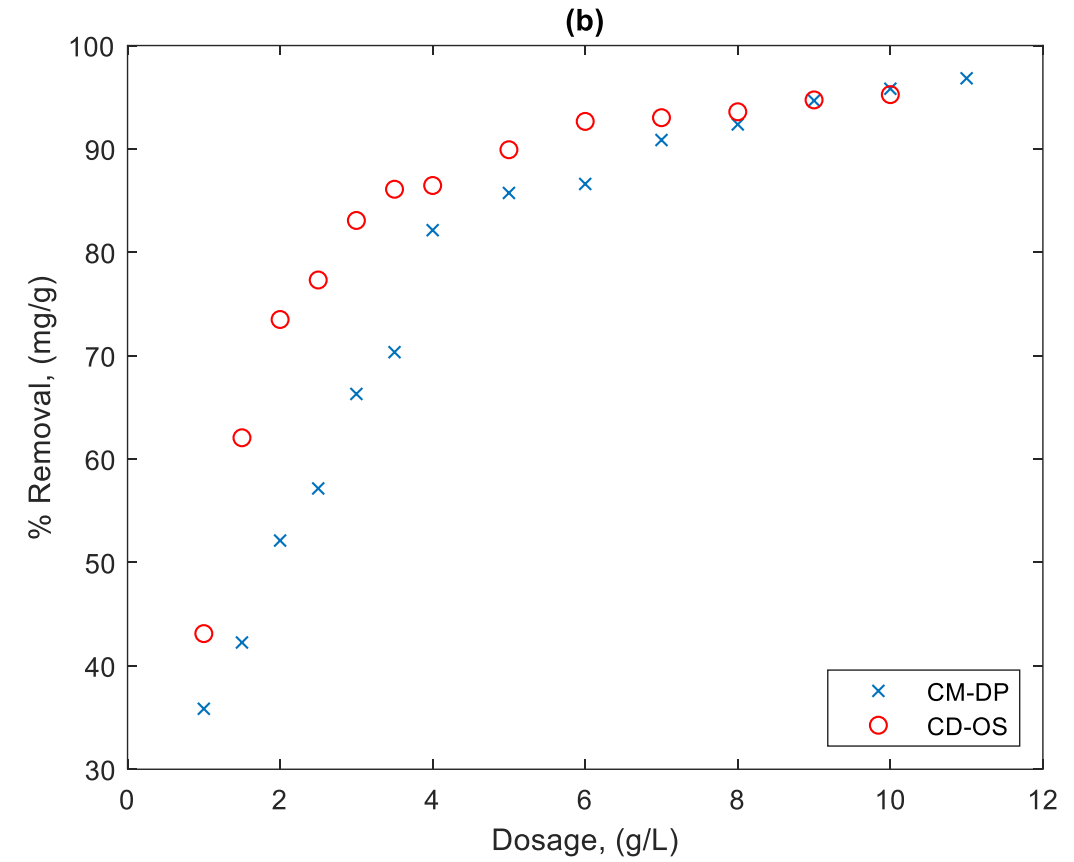

Figure 5: effect of dosage on (a biosorption capacity (b) percentage removal of Cr(VI). 

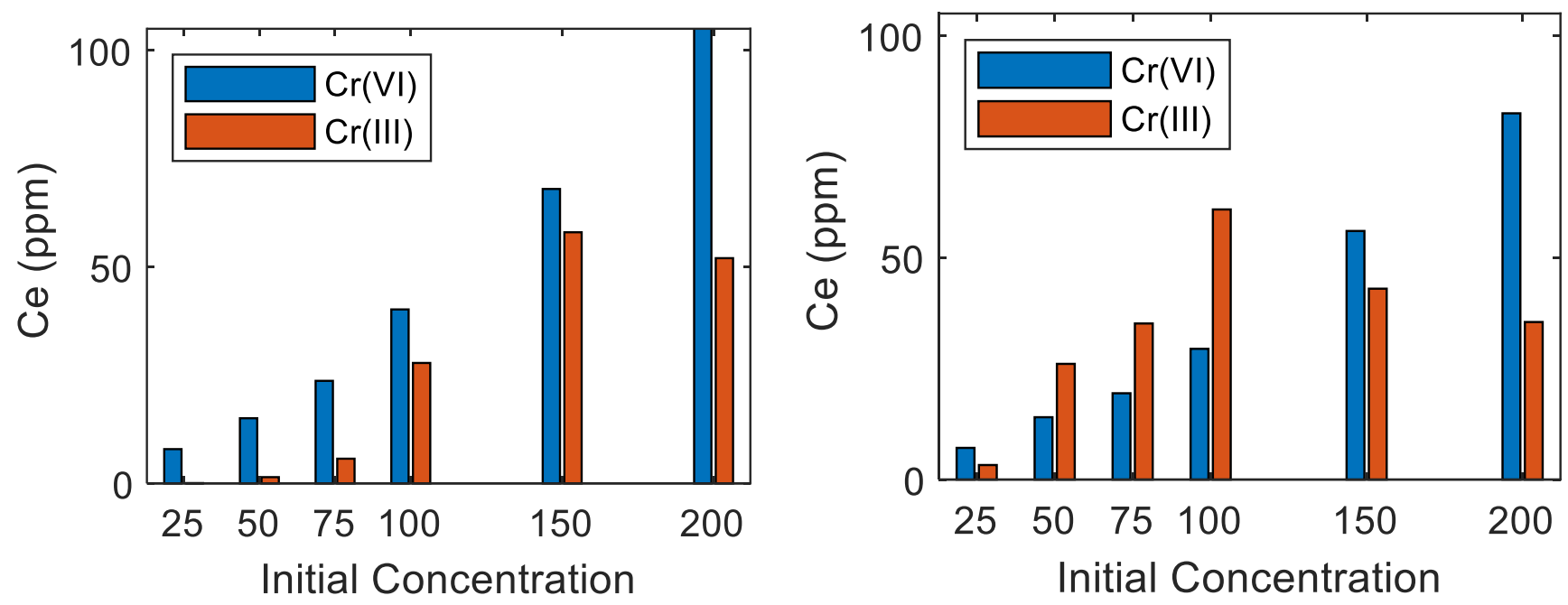

Figure 6: Effect of initial solution concentration on the reduction of $C r(V I)$ to $C r(I I I)$ : CM-DP (right) and CM-OS (left). 
(a)

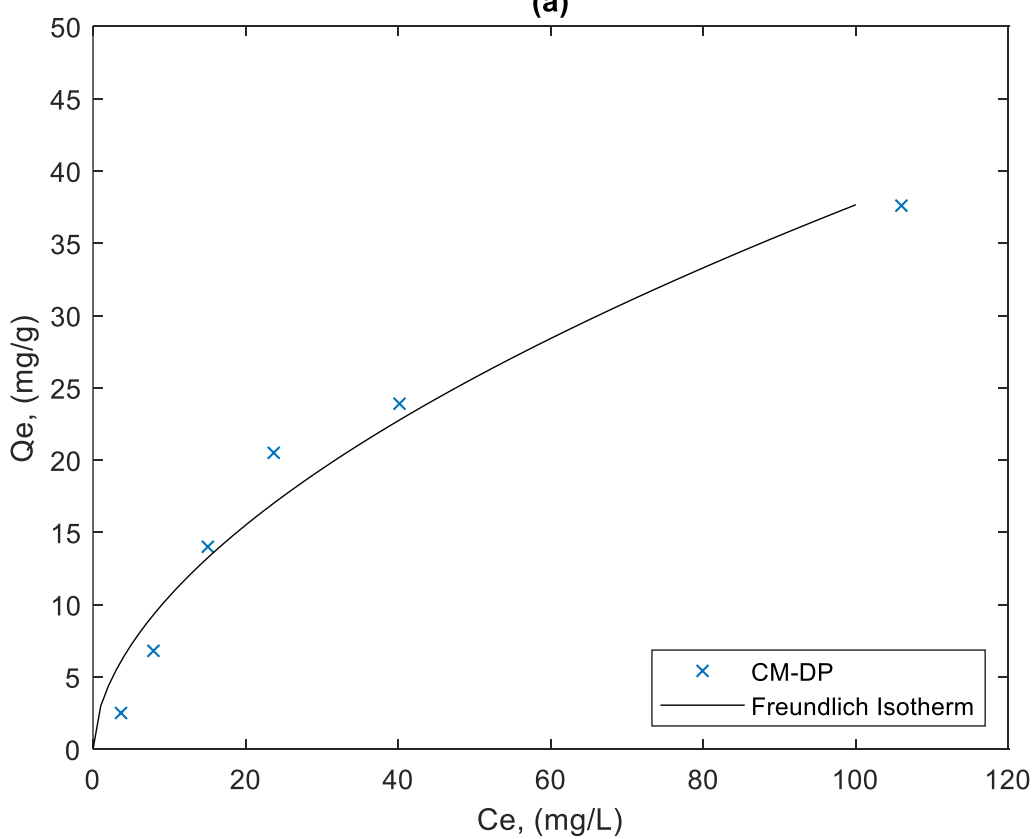

(b)

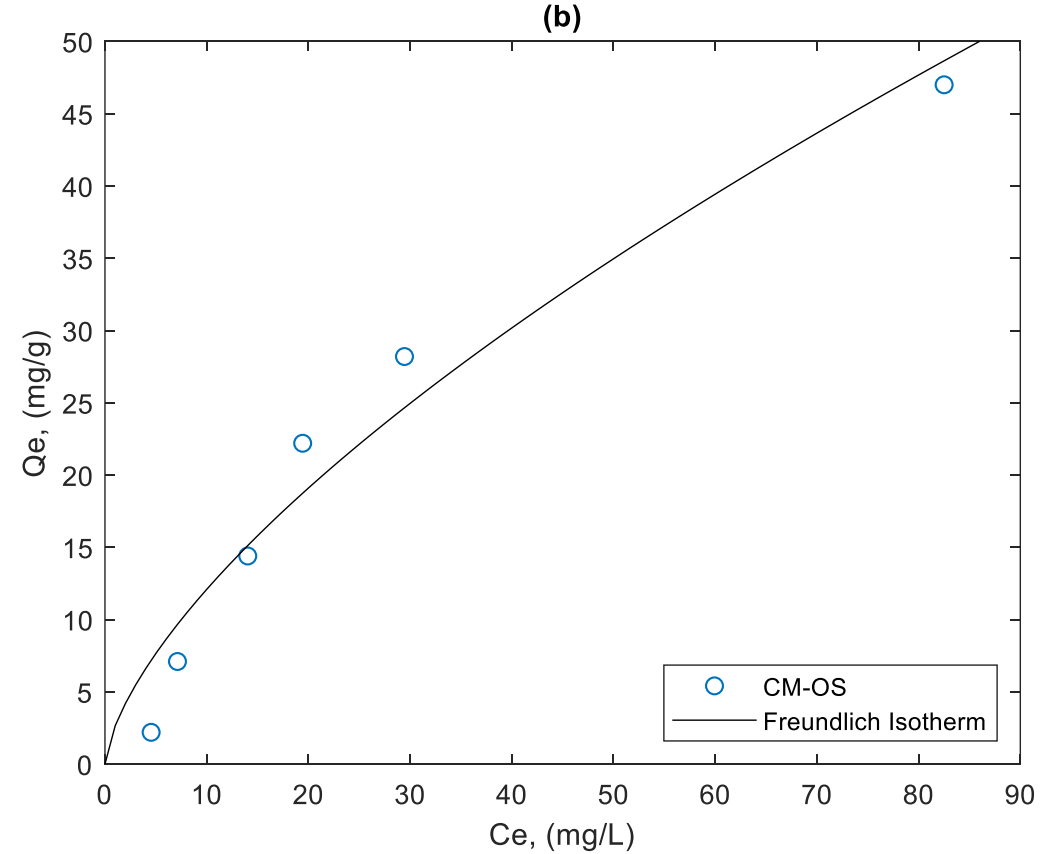

Figure 7: Isotherm plots for chemical modified date pits (CM-DP) and chemically modified olive stone (CM-OS) Experimental conditions: solution $\mathrm{pH}: 2 ; 2.5 \mathrm{~g} / \mathrm{L}$; shaking time 3 days at $110 \mathrm{rpm}$;room temperature. 
(a)

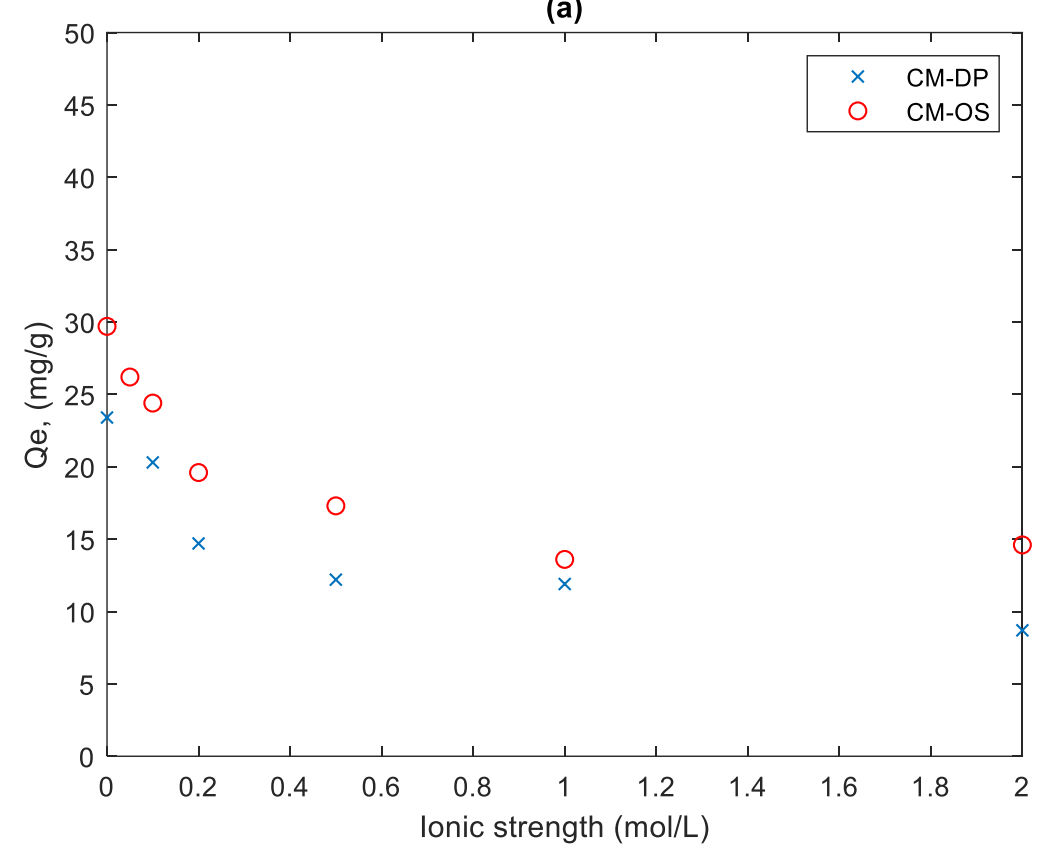

(b)

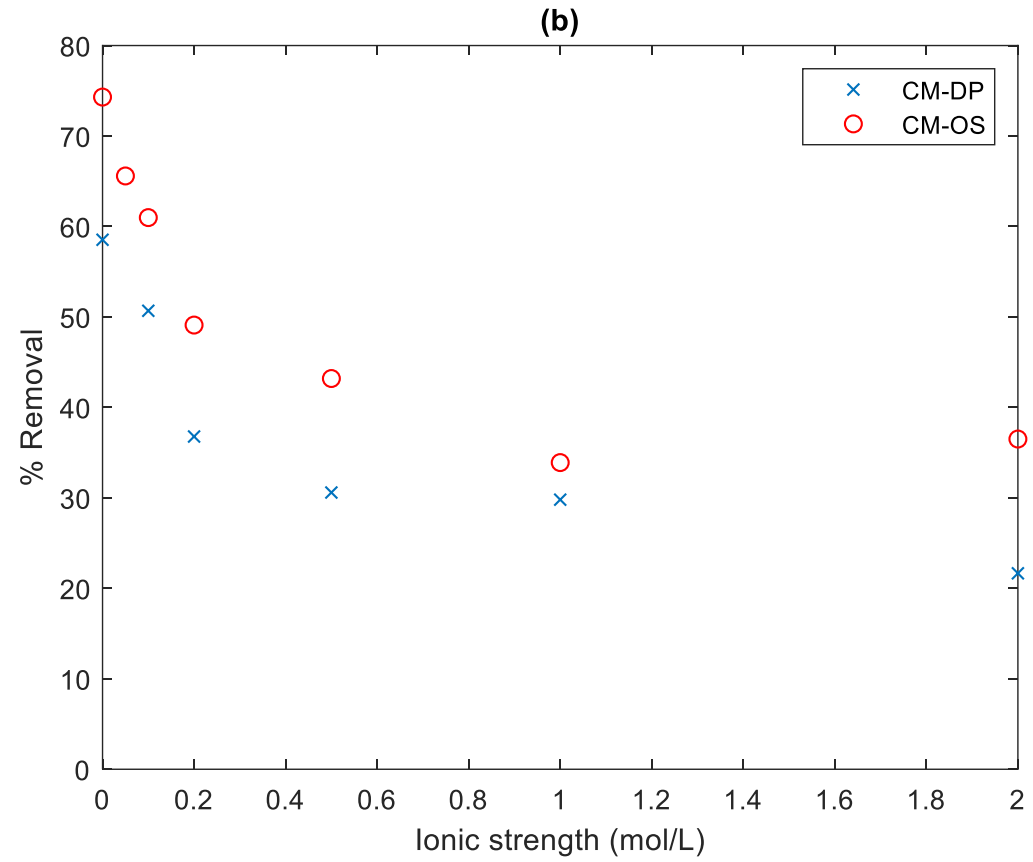

Figure 8: Effect of ionic strength of the effluent on (a biosorption capacity (b) percentage removal of $\mathrm{Cr}$ (VI). 
(a)

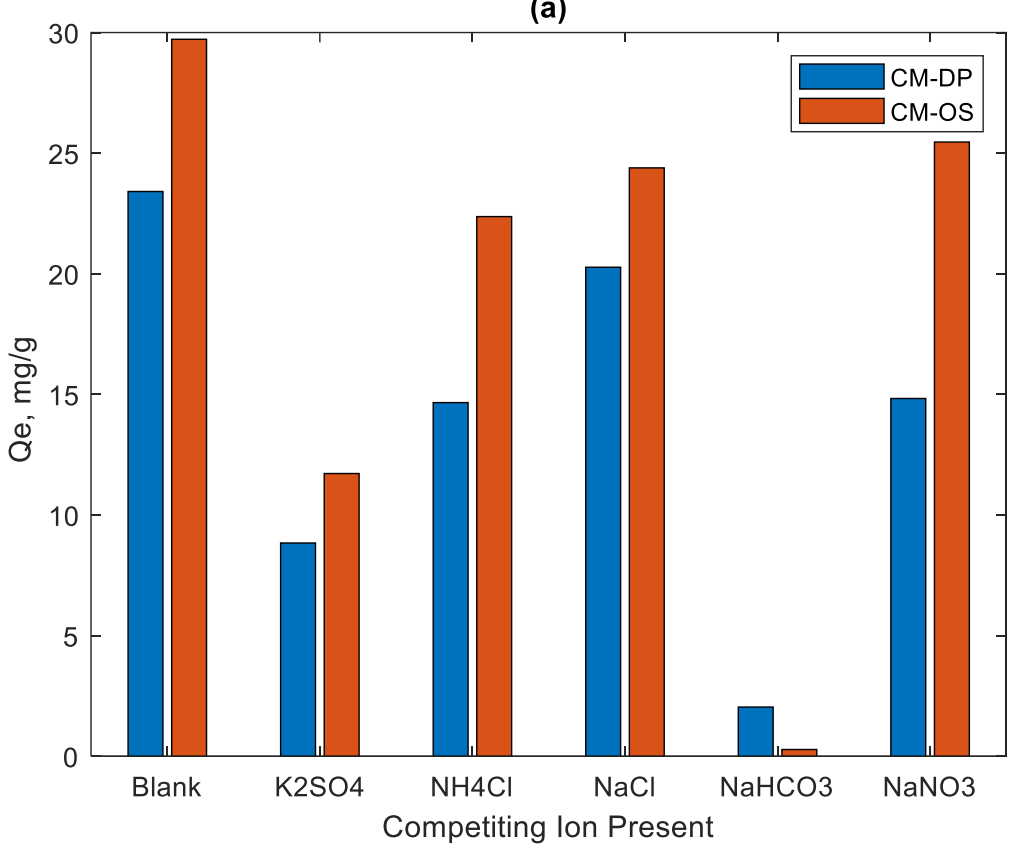

(b)

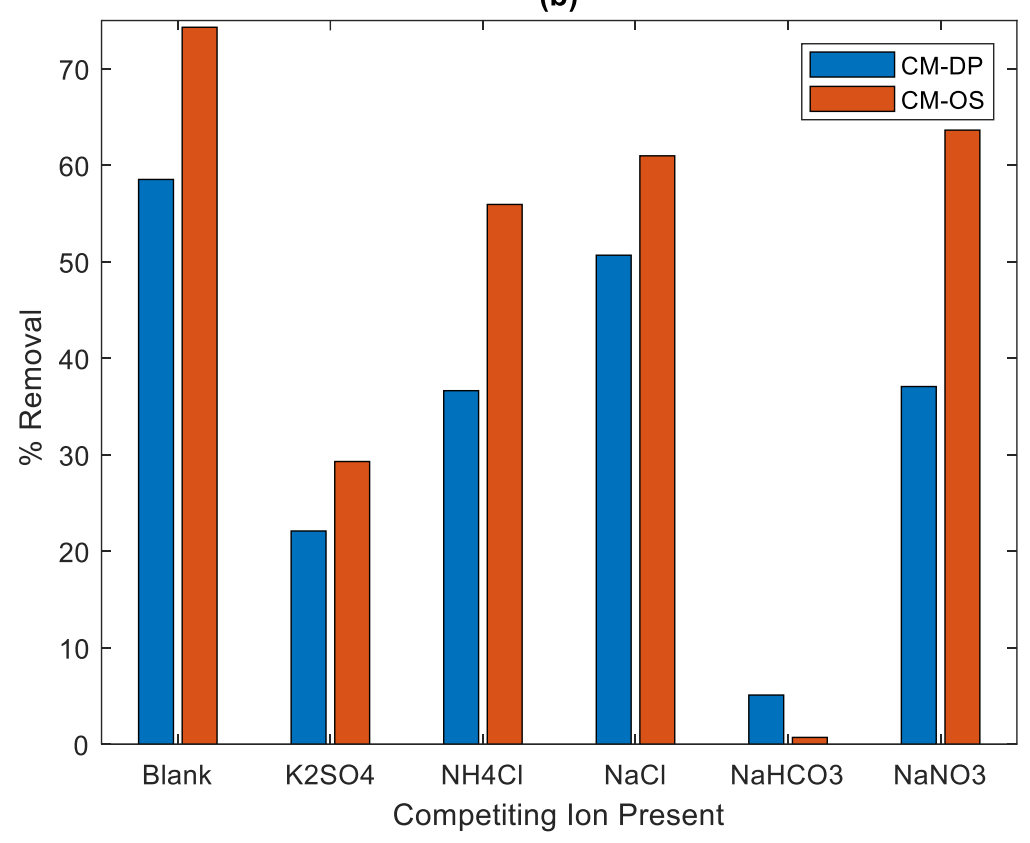

Figure 9: Effect of presence of other ions in effluent on (a) concentration of $C r(V I)$ in solid phase (b) Percentage removal of Cr(VI). 

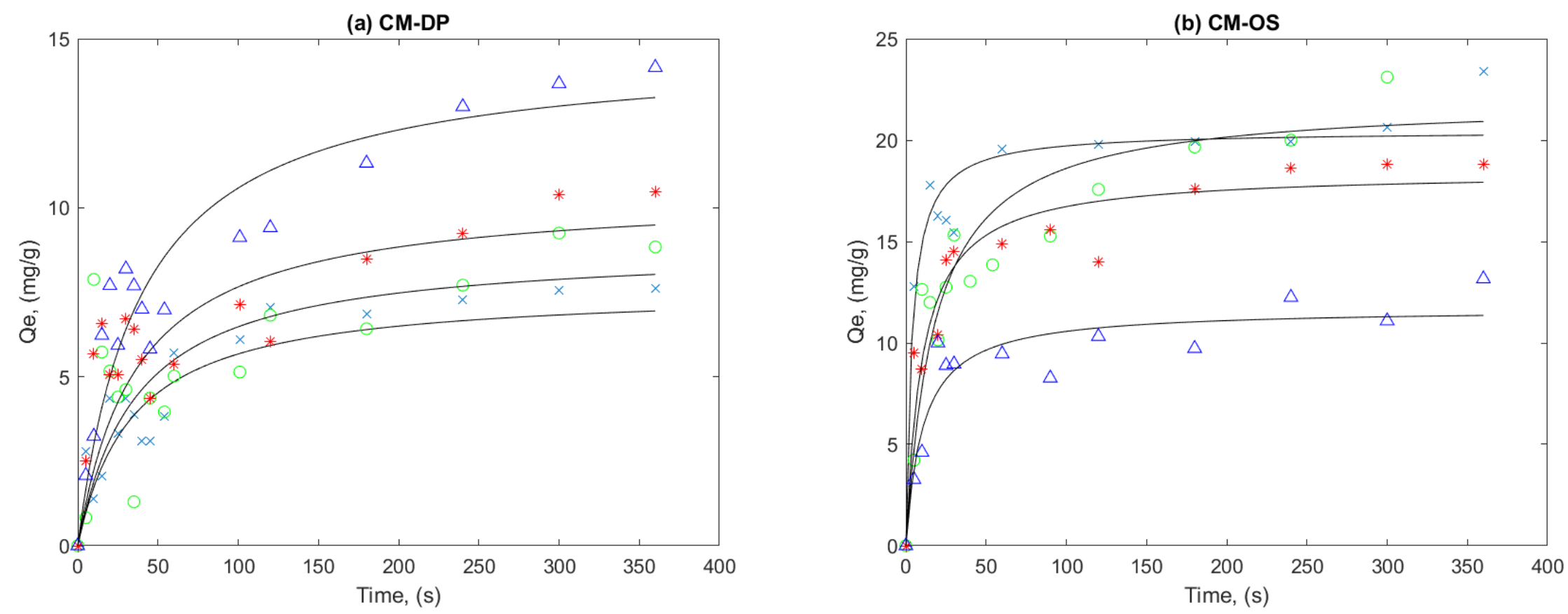

Figure 10: Influence of temperature on the kinetics of biosorption of $C r(I V)$ on to (a) CM-DP and (b) CM-OS. The intial concentraiton of the solutions were $100 \mathrm{ppm}$ and a dosage ratio of $2.5 \mathrm{~g} / \mathrm{L}$. pH of the solution was adjusted to ph2. In this figure the diferent symbol show different temperatures $(x) 20^{\circ} \mathrm{C},(\mathrm{o}) 30^{\circ} \mathrm{C},\left(^{*}\right) 40^{\circ} \mathrm{C}$ and (A) $50^{\circ} \mathrm{C}$; the continous line is a plot of equation 5. 
